\title{
Assessing the cumulative impact of disturbance on canopy structure and chemistry in Appalachian forests
}

\author{
Lindsay N. Deel \\ West Virginia University
}

Follow this and additional works at: https://researchrepository.wvu.edu/etd

\section{Recommended Citation}

Deel, Lindsay N., "Assessing the cumulative impact of disturbance on canopy structure and chemistry in Appalachian forests" (2010). Graduate Theses, Dissertations, and Problem Reports. 891. https://researchrepository.wvu.edu/etd/891

This Thesis is protected by copyright and/or related rights. It has been brought to you by the The Research Repository @ WVU with permission from the rights-holder(s). You are free to use this Thesis in any way that is permitted by the copyright and related rights legislation that applies to your use. For other uses you must obtain permission from the rights-holder(s) directly, unless additional rights are indicated by a Creative Commons license in the record and/ or on the work itself. This Thesis has been accepted for inclusion in WVU Graduate Theses, Dissertations, and Problem Reports collection by an authorized administrator of The Research Repository @ WVU. For more information, please contact researchrepository@mail.wvu.edu. 


\title{
ASSESSING THE CUMULATIVE IMPACT OF DISTURBANCE ON CANOPY STRUCTURE AND CHEMISTRY IN APPALACHIAN FORESTS
}

\author{
Lindsay N. Deel \\ Thesis submitted to the \\ Eberly College of Arts and Sciences \\ at West Virginia University \\ in partial fulfillment of the requirements for the degree of
}

Master of Arts

In

Geography

Brenden E. McNeil, Ph.D., Chair

Timothy A. Warner, Ph.D.

William T. Peterjohn, Ph.D.

\section{Department of Geology and Geography}

Morgantown, West Virginia

2010

Keywords: forest ecology, disturbance, remote sensing, eastern forests, ecosystem ecology

Copyright 2010 Lindsay N. Deel 


\section{ABSTRACT \\ Assessing the cumulative impact of disturbance on canopy structure and chemistry in Appalachian forests}

\section{Lindsay N. Deel}

Eastern forests experience a range of disturbance events over time, from stand-replacing disturbances, such as clear cuts, to ephemeral disturbances, such as insect outbreaks. By understanding the cumulative impact of disturbances on canopy structure and chemistry, we can gain insight into management strategies, assess a variety of ecosystem services, and even contribute to a larger body of knowledge on global climate change. I transformed a series of Landsat images spanning approximately 25 years into cumulative disturbance maps covering Green Ridge State Forest and Savage River State Forest in western Maryland. Intensive field surveys collected during the summer of 2009 provided measurements of canopy $\mathrm{N}$ and estimates of canopy cover, understory cover, and leaf cover. I used AVIRIS imagery flown concurrently with field data collection to map canopy nitrogen across both forests. Through this project, I tested the impact of cumulative disturbance on forest canopy cover and canopy nitrogen. I found that increased values of cumulative disturbance had a measurable negative impact on forest canopy structure and canopy nitrogen. Moreover, by testing varying methods of summing cumulative disturbance, I found that past disturbances diminish over time in importance, yet still influence the current canopy structure and canopy $\mathrm{N}$ of a forest. Thus, my study suggests that Landsat time series data can be synthesized into cumulative metrics incorporating multiple disturbance types, which help explain important disturbance-mediated changes in ecosystem functions. 
This thesis is dedicated my wonderful family, and in particular, Walter Studenroth (Opa), who was always proud of me. I love you. 


\section{ACKNOWLEDGEMENTS}

Special thanks to the many people who have helped me get through this thesis: my academic advisor: Brenden McNeil; my committee members: Bill Peterjohn and Tim Warner; the members of the NASA TE grant team: Phil Townsend, Keith Eshleman, Shawn Serbin, and Aditya Singh; my summer field crew: Brad Breslow, Carly Parana, Craig Leibfried, and Jeff Griffith; my funding sources: NASA WVSGC, NASA TE program, and WVU; the foresters at GRSF and SRSF; and all of those who provided emotional support for me during the past two years, including my family and friends. 


\section{TABLE OF CONTENTS}

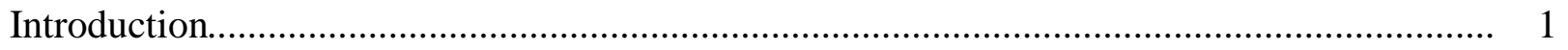

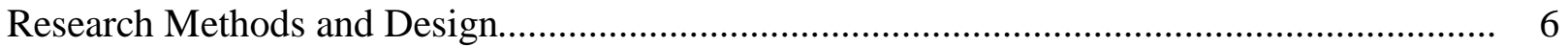

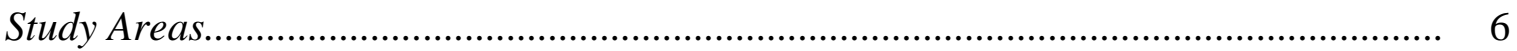

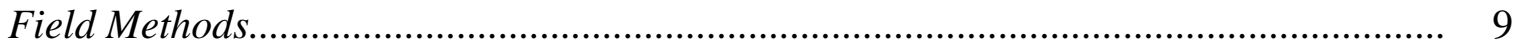

Multispectral Imagery Methods....................................................................... 12

Hyperspectral Imagery Methods........................................................................ 15

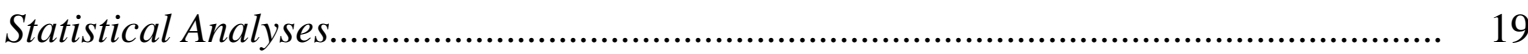

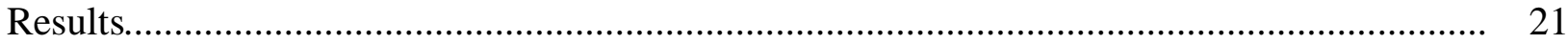

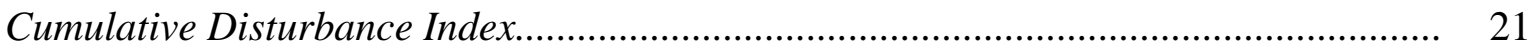

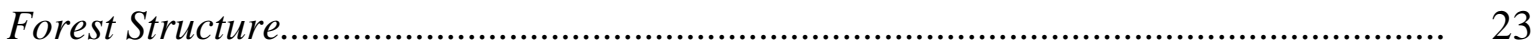

Foliar and Canopy N........................................................................................... 24

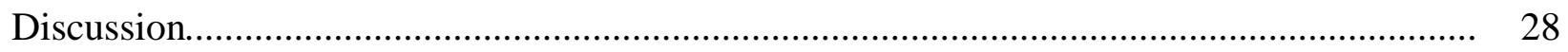

Cumulative Disturbance Index............................................................................... 28

Cumulative Disturbance Index and Forest Structure ................................................. 31

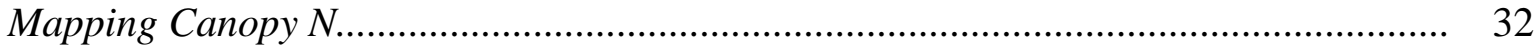

Cumulative Disturbance and Canopy N................................................................ 33

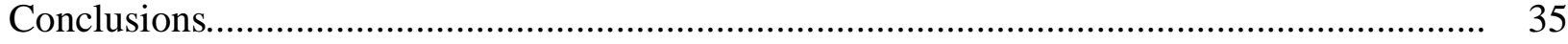

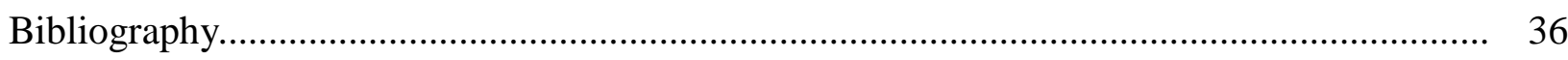

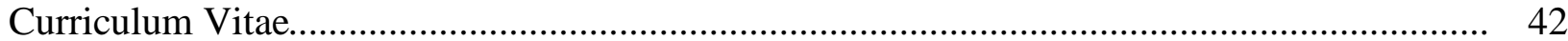




\section{LIST OF TABLES}

1: Previously existing data available for GRSF and SRSF......................................... 8

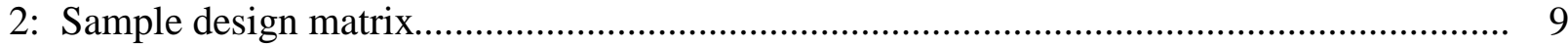

3: Landsat imagery used for the creation of cumulative disturbance indices........................ 12

4: Results of the regressions $\left(r^{2}\right)$ between forest structure variables................................... 21

5: Results of the regressions $\left(r^{2}\right)$ between canopy $\% \mathrm{~N}$ values.......................................... 25 


\section{LIST OF FIGURES}

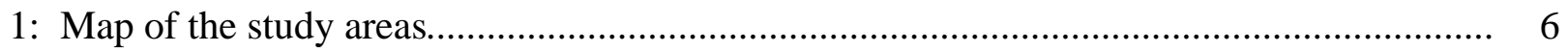

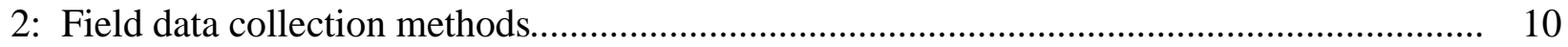

3: Flowchart of the remote sensing methods used to create cumulative DI.......................... 14

4: Conceptual diagram of the linear weighting scheme................................................... 15

5: Results of the PLS regression between plot canopy N and AVIRIS reflectance............... 17

6: Relationships between \% canopy cover..................................................................... 22

7: AVIRIS-derived canopy N maps for both study areas............................................... 23

8: Mean values of AVIRIS-derived canopy $\mathrm{N}$ by species type......................................... 24

9: The relationship between \% canopy N..................................................................... 26

10: Qualitative assessment of the accuracy of cumulative DI.............................................. 29 


\section{INTRODUCTION}

Ecosystem services include processes and resources provided by the natural environment that, in some way, benefit humanity. For example, many Appalachian forest ecosystems currently provide ecosystem services of carbon $(\mathrm{C})$ sequestration and nitrogen $(\mathrm{N})$ retention. By taking in more atmospheric carbon dioxide $\left(\mathrm{CO}_{2}\right)$ during photosynthesis than they release during respiration, these forest ecosystems can reduce atmospheric concentrations of $\mathrm{CO}_{2}$, staving off the effects of climate change. Similarly, the ability of a forest to retain $\mathrm{N}$ from atmospheric deposition (e.g. acid rain) provides protection from acidification and eutrophication in streams and estuaries, processes that can endanger fisheries and human health (Likens et al. 1970, Driscoll et al. 2003). Interestingly, these Appalachian forest ecosystem services are fundamentally linked through a single, measureable variable, the concentration of $\mathrm{N}$ in leaves of the canopy (i.e. canopy N). At the plant level, foliar $\mathrm{N}$ exerts a strong control over rates of photosynthesis (Evans 1989, Wright et al. 2004), and of forest productivity and carbon sequestration at the canopy level (Smith et al. 2002, Pan et al. 2004, Ollinger et al. 2009). Canopy $\mathrm{N}$ is also related to the ability of a forest to retain atmospheric $\mathrm{N}$ deposition (Aber et al. 1998).

Remote sensing of canopy $\mathrm{N}$ through the use of hyperspectral instruments has greatly expanded the scale at which canopy $\mathrm{N}$ may be observed, enabling studies to be carried out across entire forested landscapes. Wessman et al. (1988) were among the first to make use of the Airborne Imaging Spectrometer (AIS) to estimate canopy lignin and $\mathrm{N}$ content in Wisconsin. Imaging spectrometers are used to infer absorption and scattering properties from the radiance of natural surfaces that correspond with chemical bonds and structure, creating characteristic and detailed spectra (Ustin et al. 2004). Wessman et al. (1988) recognized specific absorption properties within specific wavelength ranges that corresponded with lignin and canopy water content. Other studies focused on identifying statistical relationships between wavelength regions and absorption properties associated with canopy chemistry (Asner 1998, Curran 1989, Peterson and Hubbard 1992, Kokaly 2001). Building on these early studies, later efforts combined the statistical relationships with models of ecosystem function to predict net ecosystem productivity in eastern forests (Martin and Aber 1997, Ollinger and Smith 2005). In 2008, Martin et al. proposed a generalized algorithm for detecting canopy $\mathrm{N}$ across a range of ecosystem types. More recently, Ollinger et al. (2009) reported on a previously unexplored relationship between canopy $\mathrm{N}$, carbon assimilation, and albedo, further linking canopy $\mathrm{N}$ to climate change and opening up the possibility of mapping canopy $\mathrm{N}$ using broadband satellites. Incidentally, this study highlighted a portion of the central Appalachian forests as a canopy $\mathrm{N}$ hotspot, suggesting a strong need for research focused on the drivers of canopy $\mathrm{N}$ variability in this area. Increased availability of hyperspectral imagery, including the proposed launch of new NASA sensors, and knowledge about calibration and validation methods will likely further 
increase interest in using canopy $\mathrm{N}$ to map broad-scale patterns of nutrient cycling and other aspects of forest function. Coupled with these technical advances, work is also needed to further understand the drivers of variability in canopy $\mathrm{N}$, including its response to forest disturbance.

White and Pickett (1985) proposed the following definition of disturbance: “...any relatively discrete event in time that disrupts ecosystem, community, or population structure and changes resources, substrate availability, or the physical environment." Whether they are standreplacing disturbances, such as clear-cut logging, or ephemeral disturbances, such as insect defoliations, disturbances affect the structure and function of forests, and can leave legacies that last for decades or even centuries after the initial disturbance events (Foster et al. 2003, Goodale and Aber 2001, Latty et al. 2004). Since these legacies are often manifested in the form of reduced nutrient availability (Townsend et al. 2004, Eshleman et al. 1998, Vitousek et al. 1979, McNeil et al. 2007), and through reduced canopy cover (Bormann and Likens 1979, Likens et al. 1978), disturbance legacies have significant impacts on the biogeochemical cycling of $\mathrm{N}$ and carbon. For example, one recent study in Green Ridge State Forest, Maryland (GRSF, Figure 1) found that a measure of increased ephemeral gypsy moth defoliation disturbance from NASA's MODIS multi-spectral instrument was linked to subsequent decreases in canopy $\mathrm{N}$ measurements detected by NASA's AVIRIS hyperspectral instrument (McNeil et al. 2007). Indeed, most forests have a long disturbance history consisting of multiple disturbance events and land use changes, yet there remains little understanding as to the cumulative effect of these disturbances on canopy $\mathrm{N}$ and forest structure. By examining the impacts of disturbances on forest ecosystems, we can gain insight into effective management strategies, assess a variety of ecosystem services, such as carbon sequestration and nitrogen retention, and even contribute to a larger body of knowledge on global climate change.

Two of the disturbance types impacting eastern North American forests are gypsy moth defoliation and clear-cut harvesting. Gypsy moth (Lymantria dispar) defoliation represents an ongoing, ephemeral disturbance affecting eastern forests, with dominant outbreak periods occurring in approximately 8-10 year intervals and subdominant outbreaks in 5-6 year intervals (Johnson et al. 2006, Haynes et al. 2009). While displaying a slight preference for oak and aspen species, gypsy moth caterpillars are less particular during large outbreaks, acting more like a generalist species (Lovett et al. 2006). Tree mortality resulting from gypsy moth defoliation is often dependent on the prior stress level of the tree, the intensity of the outbreak, and the number of outbreaks a tree experiences within several years. Given that gypsy moth outbreaks do not necessarily kill most of the trees in the forest, its effect on forest structure is variable and often subtle, with observed decreases in oak proportion and a slight decrease in subdominant canopy species (Cambell and Sloan 1977), which may alter forest successional rates and progress and open the forest to shifts in species composition. Herbivory, in general, has a potentially large impact on plant nutrient budgets because it typically precedes resorption. Resorption is the process of retracting nutrients out of senescing leaves before they are dropped, which plays an 
important, though poorly understood, role in nutrient retention for the plant. Because of this, plants may lose twice as much $\mathrm{N}$ through herbivory than they would through senescence (Chapin et al. 2002).

Clear-cut harvesting represents a management practice commonly employed in some eastern forests, with the potential to dramatically alter forest structure by removing large amounts of biomass from the system and sparking secondary succession (Bormann and Likens 1979). Though experimental in nature, a study by Likens et al. (1978) at Hubbard Brook found that recovery of biomass and nutrients from clear-cutting can take 60-80 years with substantial nutrient losses immediately following the harvest. Moreover, repeated harvesting can potentially decrease biodiversity, sustain nutrient limitation, and create shifts in species composition (Likens et al. 1978, Vitousek and Reiners 1975, Beck and Hooper 1986).

Finding an appropriate method for reconstructing and quantifying a forest's disturbance history, especially at the landscape scale, can present a challenge. Field observations provide a useful means of tracking disturbances within a forest, but consistent measurements through time and in a spatially explicit manner are often not available. Moreover, it can be difficult to understand landscape patterns using plot-level field data. Remote sensing offers the benefit of a landscape-scale approach to ecosystem ecology, which can reveal processes that are difficult or impossible to measure in the field alone. In fact, remote sensing, in combination with ground validation data, may provide the most promising avenue for researching ecosystem changes across time (Wessman 1992). Within available remote sensing data, Landsat represents the longest running family of terrestrial observation satellites in the United States, collecting data since 1972 (Jenson 2007), and may provide one of the only methods for assessing a forest's cumulative disturbance history at the landscape scale.

Many past studies have examined the use of multitemporal Landsat TM/ETM+ imagery as a tool for assessing and quantifying disturbance across broad spatial scales using a variety of image processing methods (Collins and Woodcock 1996, Rogan et al. 2002, Wilson and Sader 2002). For example, Townsend et al. (2004) used change vector analysis (CVA) to highlight the magnitude and direction of change in response to gypsy moth defoliation. Their results suggest that Landsat imagery can be a valuable method for assessing ephemeral disturbance impacts. In another study, Jin and Sader (2005) compared the more straightforward normalized difference moisture index (NDMI) and tasseled cap wetness (TCW) index for their utility in detecting disturbance in forests. These two transformations proved to be highly correlated and very similar in their ability to detect disturbances, suggesting that the near-infrared (NIR, band 4) and shortwave infrared (SWIR, band 5) bands of Landsat appear to be particularly sensitive to forest disturbances. Kennedy et al. (2007) also used the SWIR (5) band to develop a method for characterizing disturbance dynamics in an automated approach by identifying unique temporal trajectories across a dense stack of Landsat imagery, providing further support for the utility of this Landsat band in disturbance detection and characterization. Several studies highlight that 
disturbances can often be best detected using indices which also include spectral information from additional bands. For instance, Healey et al. (2005) created the disturbance index, which combines the brightness, greenness, and wetness bands of the tasseled cap transformation to highlight disturbances in forests. Recently, Hais et al. (2009) compared the normalized difference moisture index (NDMI), tasseled cap brightness, greenness and wetness, and found a version of the disturbance index to be the most sensitive measure of forest disturbance for detecting stand-replacing disturbances and discriminating spectral differences between multiple types of disturbances.

My study sought to assess the cumulative impact of disturbance by analyzing the additive affects of multiple years of disturbance on a forest. My primary objectives were to create spatially explicit maps of cumulative disturbance intensity across two distinct study areas, test the accuracy of the cumulative disturbance maps against existing GIS data, and examine the relationship between cumulative disturbance and forest canopy structure and chemistry. The broader goal of addressing these objectives was to enhance methods for mapping the spatial and temporal patterns of forest disturbances, and project their cumulative impact on the nitrogen status of eastern forests. Keeping these objectives in mind, this project explicitly addressed two major hypotheses about the relationship between canopy nitrogen, forest structure, and cumulative disturbance history:

Hypothesis 1: As cumulative disturbance increases, I expected to see a subsequent decrease in canopy $N$ at the plot, stand, and watershed scales.

Hypothesis 2: As cumulative disturbance increases, I expected to see a subsequent decrease in canopy cover and leaf cover and a subsequent increase in understory cover.

This project was also designed to explore the nature of cumulative disturbance as it relates to canopy $\mathrm{N}$ and forest structure, as well as the scale at which these relationships can be observed. Since there has been no real consensus on the temporal trajectories of forest recovery from disturbance, I expected that this project would contribute to this growing literature within eastern forests. In order to begin exploration on this idea, I formulated three sub-hypotheses to test the temporal nature of recovery and disturbance legacies:

Research sub-hypothesis 1: Disturbances are cumulative in nature, and every past year of disturbance influences the current structure and chemistry of a forest to an equal degree.

Research sub-hypothesis 2: Past disturbances in a forest diminish over time in importance, yet still influence the current structure and nutrient status of a forest. 
Null sub-hypothesis: Change maps of the current condition of a forest are sufficient to explain patterns in the canopy structure and chemistry of that forest.

I focused my analysis on three major scales: the plot-, stand-, and watershed-scales. Cao and Lam (1997) define operational scale as "the scale at which certain processes operate in the environment." In order to observe a phenomenon, it is important to match the observational scale to the operational scale, but this is typically not a straightforward process. Identifying the appropriate scale of analysis often involves an exploratory process of testing observations at different scales. The plot-level analyses relied exclusively on field-measured data that I aggregated to the plot-scale. Stand-level analyses focused on the relationship between cumulative disturbance, canopy structure, and chemistry within similar species types or associations, defined using GIS species composition maps of the study areas. The stand scale is based on the fact that $\mathrm{N}$ availability and cycling have been shown to vary quite dramatically across species types (Lovett et al. 2004, Chapman et al. 2006, Lovett and Tobiessen 1993, and McNeil et al. 2008). These differences between species pose a potential limitation on the amount of variability that can be detected between plots of varying disturbance history, creating a need for evaluation at the stand-scale in addition to the plot scale. The watershed-level analysis was the broadest scale of analysis, and relied on the remote sensing data, aggregated to drainage basins in the study areas. The watershed scale was designed to average out differences resulting from species composition or other sources of finer scale variability. The typical watershed area was greater than $0.8 \mathrm{~km}^{2}$. The idea of scale is an important component of this project, and the three-fold structure of my analysis should provide insight into the operational scale of $\mathrm{N}$ limitation resulting from cumulative disturbance. 


\section{RESEARCH METHODS AND DESIGN}

\section{Study Areas}

I conducted my research within two study areas: Green Ridge State Forest (GRSF) and Savage River State Forest (SRSF), both in western Maryland. These areas are delineated by the forest boundaries, but slightly expanded to include the complete hydrological unit codes (HUCs) at the HUC-11 level. GRSF is an oak-dominated forest in the Ridge and Valley physiographic province of the Appalachian highlands in Allegheny County, Maryland (Figure 1). The surface geology of GRSF is predominantly shale and sandstone with elevations ranging from approximately 138 to 620 meters above mean sea level, with an average elevation of about 300

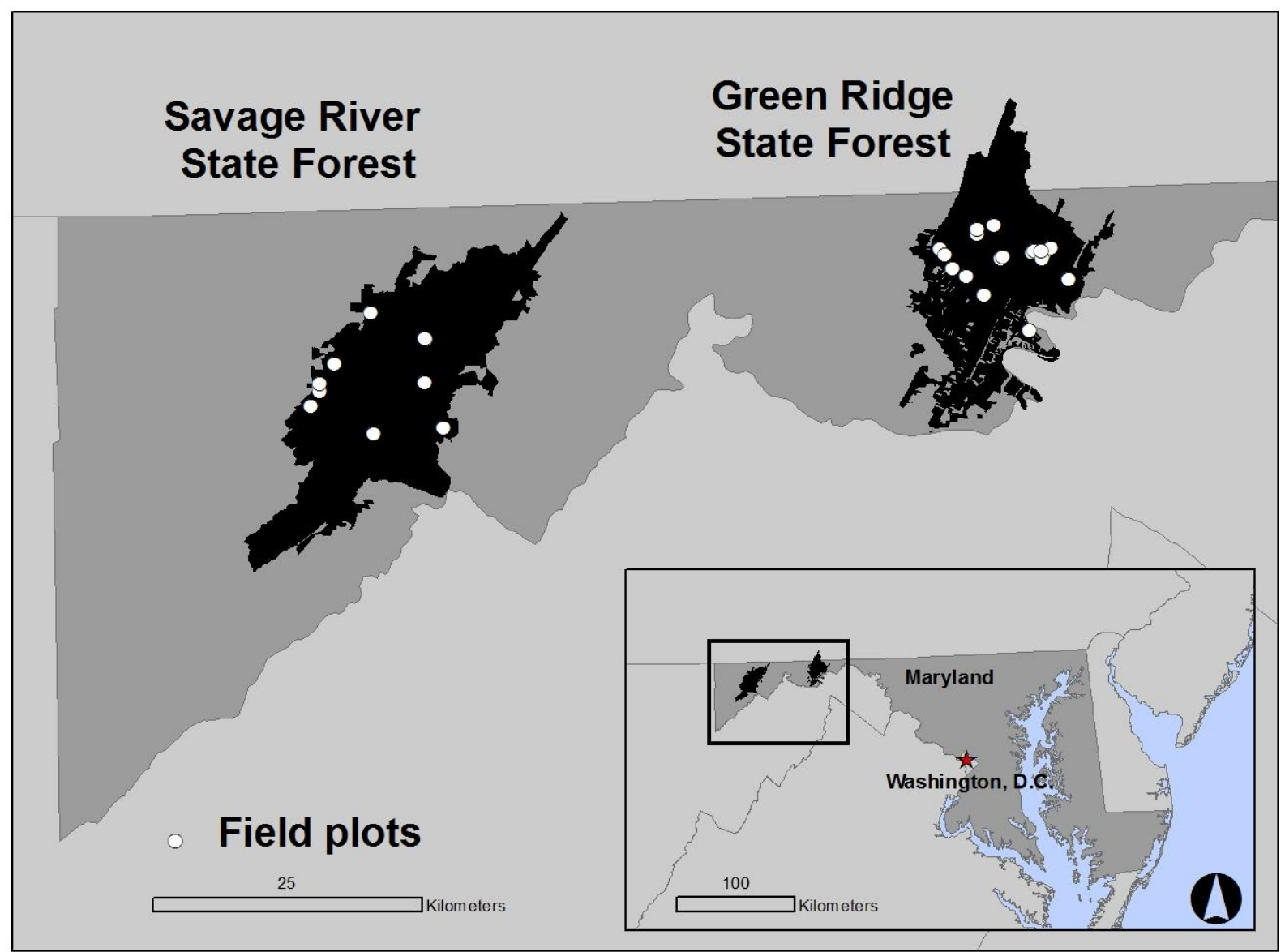

Figure 1: Map of the study areas with field plots indicated by the white circles. 
meters (Townsend et al. 2004). In conjunction with $\mathrm{N}$ availability, soil moisture is a major limiting factor in this environment. Most of the soils in GRSF are derived from the shale bedrock and are less than half a meter deep. These shaley silt loam soils have the lowest water holding capacity in Alleghany County, Maryland, and are rapidly depleted during drought periods (Mash 1996). Also contributing to the moisture-limited environment of GRSF is its position in the rain shadow of the Alleghany front, which limits annual precipitation to only 91 centimeters annually (Foster and Townsend 2004). Deciduous oaks dominate GRSF, though Virginia pine (Pinus virginiana), white pine (Pinus strobus), eastern hemlock (Tsuga canadensis), and several hickory species (Carya spp.) are also quite abundant. White oak (Quercus alba) was historically and is still presently the most abundant tree species in GRSF, but other important oak species include chestnut oak (Quercus prinus), black oak (Quercus velutina), scarlet oak (Quercus coccinea), and northern red oak (Quercus rubra).

As detailed in a thorough environmental history provided by Mash (1996), GRSF was almost entirely cleared at the beginning of the twentieth century due to a failed attempt at creating the world's largest apple orchard. Extensive logging throughout the $1800 \mathrm{~s}$ left much of the forest virtually devoid of timber and financially worthless, which prompted the idea of converting this "worthless" land into a vast orchard in the tradition of such successful ventures as those in the Pacific Northwest. Within about six years from 1910 until the beginning of 1917, the land was converted and planted, but due to a combination of shady business practices and the great Depression, eventually failed as a viable business opportunity. After a series of attempts to salvage and sell off the land, the state of Maryland began purchasing the land in 1932, naming the state forest Belle Grove State Forest, and eventually changing the name to Green Ridge State Forest. By the 1970s, GRSF was approximately its current acreage (51,000 acres), but there are still scattered, privately-owned tracts that the state continues to purchase as funds become available. Since the inception of GRSF, there have been several major outbreaks of gypsy moth defoliation, most recently in 2000, as well as continued timber harvesting.

SRSF is a mixed mesophytic forest in the Allegheny Plateau physiographic province of the Appalachian highlands in Garrett County, Maryland (Figure 1). Unlike GRSF, the climate in SRSF is generally moist and cool due to its position on the windward side of the Alleghany front with an average annual precipitation of about $120 \mathrm{~cm}$ (Chastain et al. 2006). The average elevation is 745 meters (about 445 meters higher than that of GRSF) and the highly dissected topography ranges from a minimum elevation of 374 to 940 meters. Shales and sandstones are the primary bedrock material, forming the major soil associations. The moist climate and varied topography create a species mixture characteristic of both northern and southern forests (Schaefer and Brown 1991). Common species include northern red oak (Quercus rubra), chestnut oak (Quercus prinus), white oak (Quercus alba), black cherry (Prunus serotina), eastern hemlock (Tsuga canadensis), red maple (Acer rubrum), and sugar maple (Acer saccharum). SRSF also contains conifer plantations where Norway spruce (Picea abies), red 
Table 1: Previously existing data available for GRSF and SRSF

\begin{tabular}{|l|l|}
\hline Data & Source \\
\hline Timber Harvest GIS Shapefiles & $\begin{array}{l}\text { Forest managers at GRSF and SRSF (1969 - } \\
2001)\end{array}$ \\
\hline Gypsy Moth Defoliation Shapefiles & United States Forest Service $(1984-2008)$ \\
\hline Species Composition Maps & Foster and Townsend 2004 (2000) \\
\hline Landsat Imagery & $\begin{array}{l}\text { NASA/USGS }(1984,1987,1999,2000,2001, \\
\text { 2002, 2005, 2006, 2007, 2008) }\end{array}$ \\
\hline AVIRIS Imagery & NASA $(2001,2009)$ \\
\hline Canopy N maps & Townsend et al. 2003 (2001) \\
\hline
\end{tabular}

pine (Pinus resinosa), Scotch pine (Pinus sylvestris), European larch (Larix decidua), white pine (Pinus strobus), pitch pine (Pinus rigida), and red spruce (Picea rubens) have been planted. Oak species account for about $60 \%$ of the growth in SRSF. The clearing of land by logging in the early $20^{\text {th }}$ century has resulted in a generally even-aged (70-90-year-old) second growth forest with a high diversity of species (Schaefer and Brown 1991).

In the early 1800s, the majority of SRSF was cleared for agriculture by private landowners following a settlement boom in Garrett County, Maryland, and often destructive, railroad-facilitated clear-cutting and burning in the area began in 1900-1912 (Schaefer and Brown 1991). The state of Maryland began purchasing land in Garrett County in 1929 and 1930, with continuing accumulation from 1930-1960, and developed management practices aimed at conservation and more responsible timber harvesting in SRSF (Schaefer and Brown 1991). The first notable defoliation by gypsy moth caterpillars occurred in 1986, and defoliation has continued to occur in a semi-cyclical pattern every 10-15 years, seriously affecting oak growth rates in particular (Schaefer and Brown 1991). Since these defoliations began in 1986, is it estimated that approximately $20 \%$ of oak growth has been lost, which account for about $12 \%$ of the total forest growth in SRSF. When normal regrowth is considered, these defoliation events have resulted in an approximately 8\% decrease in forest growth (Schaefer and Brown 1991).

Thus, within these two study areas, there have been a variety of disturbances over the past two centuries, including forest clearing and conversion to an apple orchard in the late 1800s and early 1900s, continued forest management (e.g. logging) since the 1970s, and several major gypsy moth defoliations during the past two decades. The availability of data and their unique disturbance histories make these sites ideal locations to research the impact of perturbations on canopy $\mathrm{N}$ and forest structure. Moreover, this study builds on a unique set of existing field and 
Table 2: Sample design matrix displaying number of plots sampled within each disturbance history and species type category. Disturbance histories are as follows: N.D. $=$ not disturbed, $H=$ harvested, $\mathrm{D}_{\mathrm{e}}=$ defoliated early (pre-1991), $\mathrm{D}_{\mathrm{r}}=$ defoliated recently (post-1991), $\mathrm{D}_{\mathrm{e} \& \mathrm{r}}=$ defoliated both early and recently, and $\mathrm{H} \& \mathrm{D}=$ harvested and defoliated. N.H. refers to northern hardwood species.

\begin{tabular}{l|l|l|l|l|l|l} 
& N.D. & $\mathbf{H}$ & $\mathbf{D}_{\mathbf{E}}$ & $\mathbf{D}_{\mathbf{R}}$ & $\mathbf{D}_{\mathbf{E} \& \mathbf{R}}$ & $\mathbf{H} \& \mathbf{D}$ \\
\hline Oak & 3 & 2 & 2 & 2 & 1 & 2 \\
\hline N.H. & 1 & 2 & 3 & 2 & 1 & 3 \\
\hline Conifer & 2 & 3 & 1 & 2 & 1 & 3
\end{tabular}

GIS data available for GRSF and SRSF (Table 1), and will serve to compliment continuing research taking place in these study areas.

\section{Field Methods}

The field data collection for this research was designed to provide thorough calibration and validation for the observations made using remotely sensed imagery. In fact, the field data was collected in such a way as to provide a stand-alone method of addressing my research objectives that fully compliments, but was not dependent upon, remote sensing analysis. I did this by first measuring chemistry at the leaf-level then scaling up to the species-level and finally scaling up further to the canopy-level. Within each study area, I chose field plots that fell within specific categories representing a range of species types and disturbance histories. I sampled from a selection of existing plots that are currently being used in research conducted by Brenden McNeil, Philip Townsend (University of Wisconsin at Madison), and Keith Eshleman (Application Laboratory, University of Maryland Center for Environmental Science) assessing the impact of forest functional types on ecosystem services. I also used GIS data to identify additional plots to supplement the existing plots; effectively creating a sampling matrix composed of varying disturbance histories and species types (Table 2). I used a random point generator in ArcGIS to identify areas suitable for supplemental plots and to limit the amount of bias involved in selecting additional plots. I identified a set of twenty-eight 60 -meter radial field plots within GRSF (18 plots) and SRSF (10 plots) that spanned the notable gradients of species types and disturbance histories.

The ancillary disturbance history data used in this project came from USDA sketch maps of gypsy moth defoliation (http://na.fs.fed.us/fhp/ta/av/) and Maryland Department of Natural Resources (DNR) maps of clear-cut timber harvests. Thinning is also practiced in these study areas, but I examined only the stand-replacing clear-cut harvests in my analyses. While the quality and accuracy of these data were evaluated by the respective sources, I do acknowledge that possible inaccuracies or scale differences may have impacted the results of my study. I sampled plots representing six levels of historical disturbance identified using the previously 


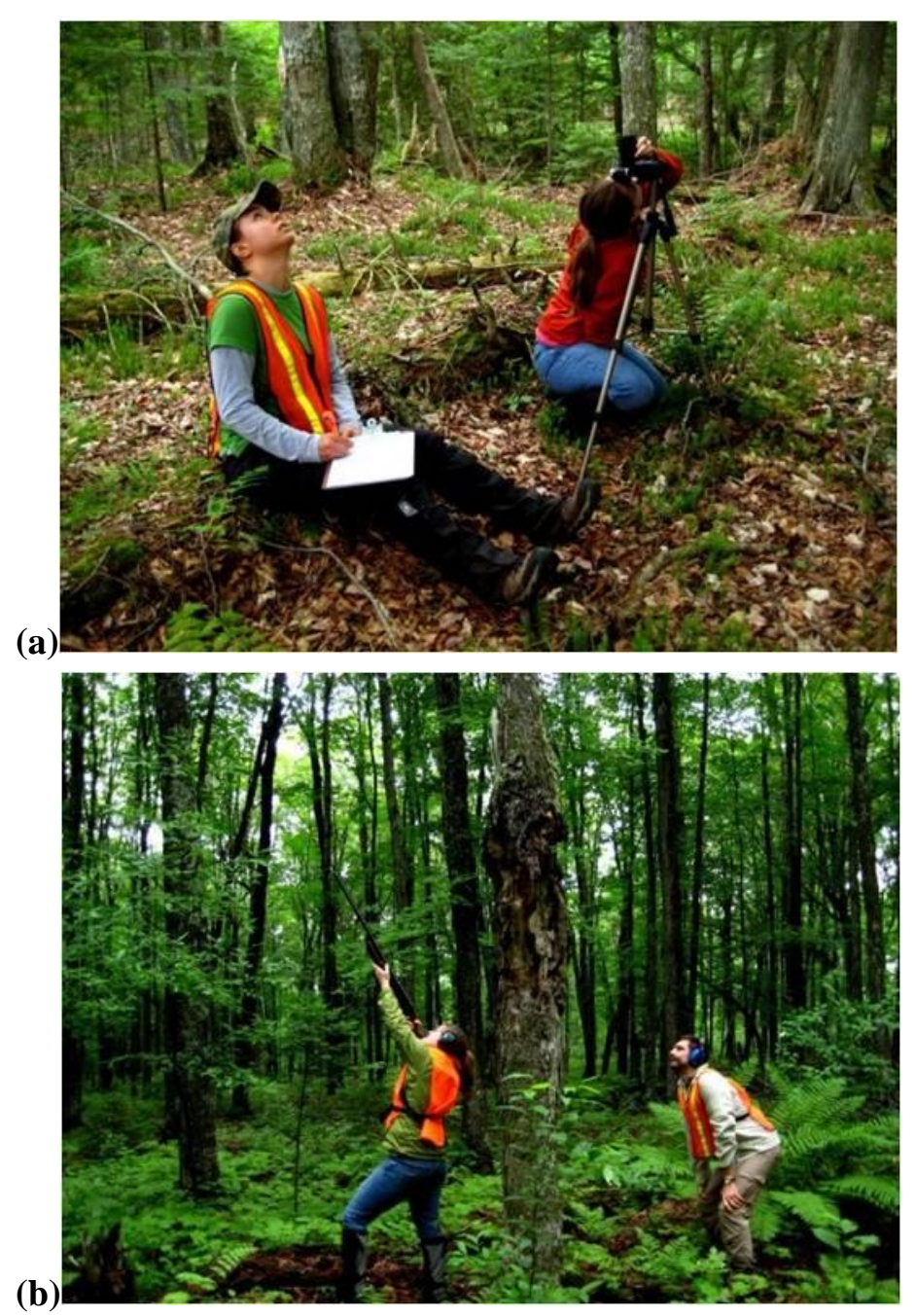

Figure 2: Field data collection methods: (a) plot-based camera point quadrat method for estimating fractional proportion of species in canopy and (b) shotgun method for collecting fresh green leaf samples for analysis of canopy chemistry.

described data: not disturbed, harvested, harvested and defoliated, defoliated early (pre-1993), defoliated late (post-1993), and defoliated both early and late. While the range of potential disturbance histories could be broken down further, I decided that these six categories should adequately display broad temporal patterns of disturbance within GRSF and SRSF (Table 2). I further divided my sampling matrix into three major functional types: oaks, northern hardwoods, and conifers.

We collected all field data during July 2009 to maintain phenological consistency with the planned AVIRIS flights over GRSF and SRSF. Field data collection at the plot-level consisted of performing surveys to determine the fractional proportion of each species in the canopy and collecting species-specific green leaf samples for lab analysis of foliar chemistry (Figure 2), which ultimately allowed for scaling up to the canopy level. Smith and Martin (2001) proposed a plot-based method for efficiently and effectively estimating canopy chemistry. This method combines a camera-based quadrat technique (based on methods described by MacArthur and Horn 1969 and Aber 1979) that estimates relative species composition and canopy height with leaf-level measurements of chemistry (i.e. foliar N). To ensure accurate measurements of species composition, we also compared the point-quadrat camera method with a cruising prism-based method of estimating the fractional proportion of species within each radial plot. I planned to compare the species estimates derived from both the camera method and this basal area method for their utility in predicting canopy $\mathrm{N}$ from AVIRIS imagery. 
In order to test my hypothesis that as cumulative disturbance increases, canopy cover and leaf cover will decrease and understory cover will increase, I collected detailed forest structure measurements at each of the 28 field plots. At each field plot, I collected multiple estimates of canopy and understory cover, recorded at five locations within each plot, as well as total plot summary estimates. The percent canopy cover and percent understory cover estimates included height-independent visual assessments at each of the five points within the radial plot design, while we also created a cover profile consisting of estimates for each height class at each plot. The leaf cover measurements were recorded using densitometer readings along four transects within each plot.

In addition to performing extensive plot surveys, we sampled individual trees representing dominant and subdominant species for fresh and dry leaf analysis of foliar chemistry. The number of trees collected depended on the relative dominance of each species within each plot, but generally consisted of three individuals per species. We pooled samples from individuals from high, medium, and low canopy heights using a pole pruner or shotgun with steel shot to collect small twigs (Smith and Martin 2001, Townsend et al. 2003, McNeil et al. 2007). The three levels of canopy height were important to ensure the inclusion of both sun and shade leaves in the aggregated species chemistry and leaf mass per area (LMA) measurements. We transported fresh leaf samples from the field to the laboratory at West Virginia University using Ziploc bags containing moist paper towels in a portable cooler to keep wet samples fresh (Garnier et al. 2001, Vaieretti et al. 2007). We transported dry leaf samples from the field to the laboratory using paper bags.

Laboratory analysis of the field data involved two major components: the fresh analysis and the dry analysis. On the fresh leaves, we calculated LMA by measuring samples for fresh leaf mass (punching holes using a specified area for broadleaf species and scanning and calculating area for needleleaf species), and then drying and reweighing samples for dry leaf mass. The LMA measurements provided an essential element in the scaling of mass-based foliar $\mathrm{N}$ data from the leaf- to the plot-level. For the dry leaf analysis, we oven-dried all samples at $60^{\circ} \mathrm{C}$ for 48 hours and then ground them using a Willey Mill to pass through a 1-millimeter mesh screen. These ground leaf samples were then wrapped, weighed, and sent through an Automatic Elemental Analyzer EA/NA $1110 \mathrm{CNS}$ analyzer to derive percent $\mathrm{C}$ and $\mathrm{N}$ values using dynamic flash combustion for each sample collected. We then combined the LMA measurements and percent $\mathrm{N}$ values to calculate plot-level canopy $\mathrm{N}$ by using the mean species foliar $\mathrm{N}$ concentration per plot, weighted by fraction of canopy foliar mass per species at each plot (Smith and Martin 2001). Since we collected species composition data using two techniques (i.e. camera method and prism method), I used both methods to calculate plot values in order to compare the utility of each. 
Table 3: Landsat imagery used for creation of the cumulative disturbance indices.

\begin{tabular}{|l|l|l|l|l|}
\hline Image Date & Path & Row & Sensor & Study Area \\
\hline $9 / 19 / 1984$ & 16 & $32 / 33$ & Landsat TM 5 & GRSF and SRSF \\
\hline $8 / 18 / 1987$ & 17 & $32 / 33$ & Landsat TM 5 & SRSF \\
\hline $8 / 03 / 1990$ & 16 & $31 / 33$ & Landsat TM 5 & GRSF \\
\hline $8 / 22 / 1991$ & 16 & $32 / 33$ & Landsat TM 5 & GRSF \\
\hline $6 / 24 / 1993$ & 16 & $32 / 33$ & Landsat TM 5 & GRSF and SRSF \\
\hline $6 / 09 / 1999$ & 16 & 33 & Landsat TM 5 & SRSF \\
\hline $8 / 04 / 1999$ & 16 & $32 / 33$ & Landsat ETM+ & GRSF \\
\hline $8 / 22 / 2000$ & 16 & $32 / 33$ & Landsat ETM+ & GRSF \\
\hline $7 / 24 / 2001$ & 16 & $32 / 33$ & Landsat ETM+ & GRSF \\
\hline $8 / 12 / 2002$ & 16 & $32 / 33$ & Landsat ETM+ & GRSF \\
\hline $6 / 25 / 2005$ & 16 & $32 / 33$ & Landsat TM 5 & GRSF and SRSF \\
\hline $8 / 06 / 2006$ & 17 & $32 / 33$ & Landsat TM 5 & SRSF \\
\hline $8 / 25 / 2007$ & 17 & $32 / 33$ & Landsat TM 5 & SRSF \\
\hline $7 / 19 / 2008$ & 16 & $32 / 33$ & Landsat TM 5 & GRSF \\
\hline
\end{tabular}

\section{Multispectral Imagery Methods}

I took advantage of the temporal range of Landsat by using a total of 14 images spanning approximately twenty-five years ranging from 1984 until 2007 and generally covering the summer months (June - early September) (Table 3). Persistent cloud cover, common to the study areas, prevented the use of anniversary dates and images for every individual year up to the present. Since I summed the images to derive my cumulative disturbance values, I had to apply the same mask to each of the images to remove nonforested areas and clouds. Even partial cloud cover resulted in a much larger masked area for all images, so I chose to exclude images with more than a few small clouds. I created the non-forest mask using the 2001 National Land Cover Dataset (NLCD) combined with a supervised classification. I implemented the COST method of atmospheric normalization (Chavez 1996, Chandler et al. 2009), which converts digital number (DN) values to reflectance values. I tested the imagery for terrain affects and found no relationship between illumination, determined using a hillshade of the study areas, and my cumulative disturbance index values $\left(\mathrm{r}^{2}=0.0055\right)$; therefore, I did not apply a terrain correction.

As previously mentioned, Healey et al. (2005) introduced the disturbance index (DI) as a Tasseled Cap-derived measure that can be used for forest disturbance detection. The Tasseled Cap transformation is commonly used to detect forest change and reduces a Landsat image into three orthogonal components rotated to emphasize: brightness (B), greenness $(\mathrm{G})$, and wetness 
(W) (Kauth and Thomas 1976, Crist and Cicone 1984, Crist and Kauth 1986, Huang et al. 2002) (Figure 3). The DI highlights the fact that disturbed areas tend to exhibit higher brightness (B) values and lower greenness $(\mathrm{G})$ and wetness (W) values than undisturbed areas. Before calculating DI, I scaled each of the three bands (B, G, and W) (Eq. (1)) to its standard deviation above or below the mean forest value for that image (Healey et al. 2005),

$B_{r}=\left(B-B_{\mu}\right) / B_{\sigma}$

$G_{r}=\left(G-G_{\mu}\right) / B_{\sigma}$

$W_{r}=\left(W-W_{\mu}\right) / W_{\sigma}$

where, $B_{r}, G_{r}, W_{r}=$ the rescaled Brightness, Greenness, and Wetness; $B_{\mu}, G_{\mu}, W_{\mu}=$ the mean forest Brightness, Greenness, and Wetness; $B_{\sigma}, G_{\sigma}, W_{\sigma}=$ the standard deviation of forest Brightness, Greenness, and Wetness. The scaling process was important for two reasons. First, I used imagery from both Landsat $5 \mathrm{TM}$ and Landsat $7 \mathrm{ETM}+$, so the scaling allowed me to compare these data. Second, the scaling reduced potential errors that could arise from season variation since the images were not from anniversary dates. These normalized indices could then be combined in the following equation (Eq. (2), Figure 3) for calculating forest disturbance:

$D I=B_{r}-\left(G_{r}+W_{r}\right)$

This equation yielded a single band image of DI values for each date of imagery. The DI works to highlight areas within a particular image date that have been recently disturbed with high, positive DI values, areas that have recently recovered from disturbance or experienced abnormally rapid growth with low, negative DI values, and all other forest pixels, assumed to be undisturbed, falling near zero (Healey et al. 2005) (Figure 3).

One difficultly in addressing forest change detection has been actually finding pixels within an image that can be called "undisturbed" with which to compare disturbed pixels. Rather than comparing DI values with one single previous or subsequent year, I compared each yearly DI image with a $\mathrm{DI}_{\min }$ image, generated by taking the lowest, or 'least disturbed' DI value for each pixel from the stack of yearly DI images (Figure 3 ). The DI $\mathrm{I}_{\min }$ was essentially a composite of all image dates, and it provided a snapshot of the forest in its least disturbed state. This allowed me to more objectively assess the total change in DI from a relatively undisturbed state. The change detection between $\mathrm{DI}_{\min }$ and the individual yearly DI images consisted of a simple image subtraction (Eq. (3), Figure 3):

$\Delta \mathrm{DI}=\mathrm{DI}-\mathrm{DI}_{\min }$ 
Thus, the resulting $\Delta \mathrm{DI}$ images represented the change experienced from each study year to the 'least disturbed' $\mathrm{DI}_{\min }$ image. One interesting component of the $\Delta \mathrm{DI}$ images is that they essentially remove the potentially confounding influence of regrowth from the overall process of calculating cumulative disturbance. By subtracting the minimum values $\left(\mathrm{DI}_{\min }\right)$ from each $\mathrm{DI}$ image, the equation eliminates negative values, which generally correspond with regrowth. In the $\Delta \mathrm{DI}$ images, the minimum value is never less than zero (Figure 3 ).

In combining the $\Delta \mathrm{DI}$ images into my cumulative DI, I tested several different weighting schemes to aid in determining the relative importance of each year. The weighting schemes were designed to explicitly test my three sub-hypotheses about the nature of cumulative disturbance and to investigate a temporal strategy for mapping cumulative disturbance. I approached my first research hypothesis by simply summing the individual change maps into one cumulative

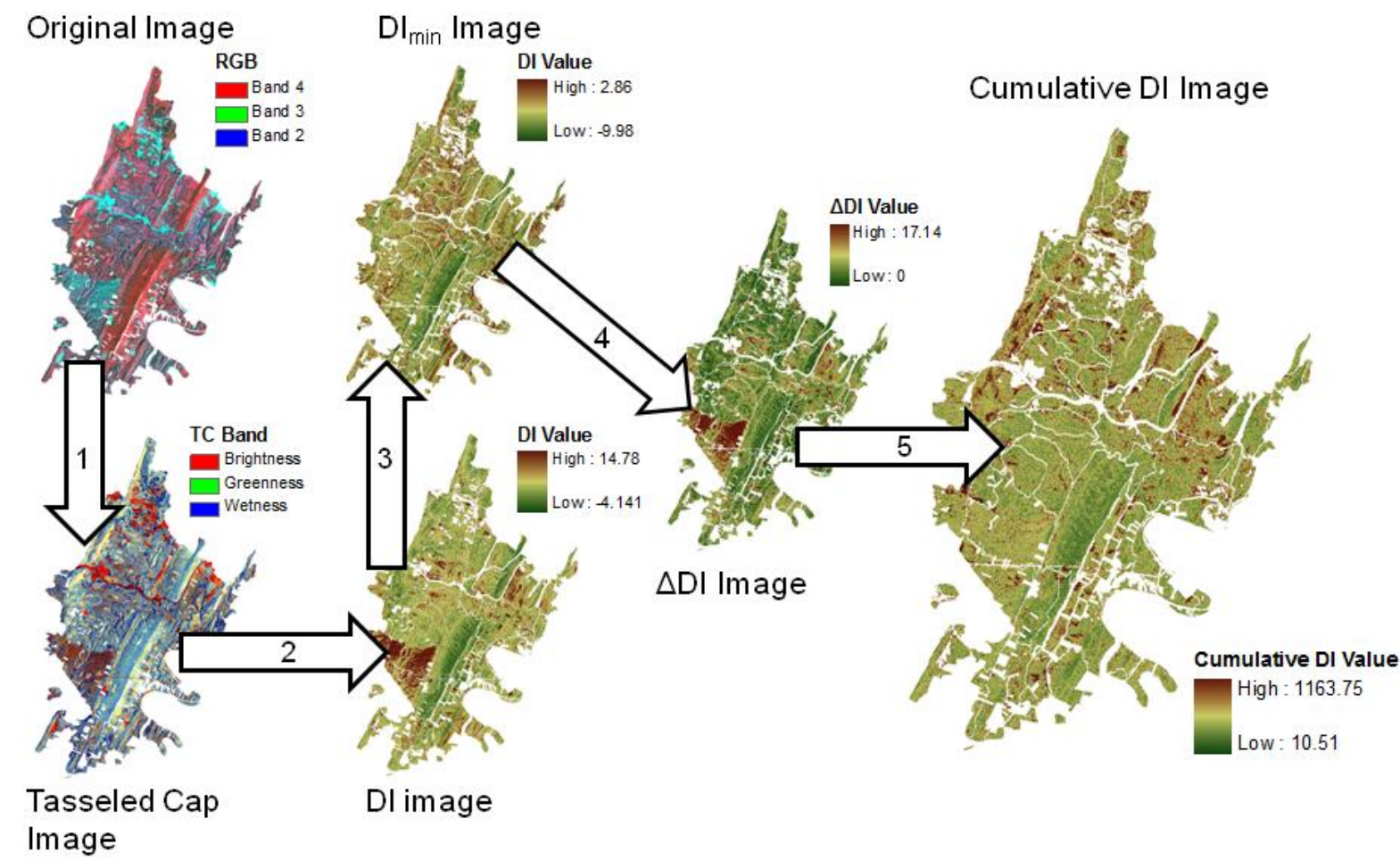

Figure 3: Flowchart of the remote sensing methods used to create the cumulative disturbance index: 1) Original image transformed using the tasseled cap transformation, 2) disturbance index (Healey et al. 2005) calculated using the tasseled cap bands, 3) minimum DI values extracted from all images to create the $\mathrm{DI}_{\min }$ image, 4) a change map, $\Delta \mathrm{DI}$, created for each year by subtracting the $\mathrm{DI}_{\text {min }}$, and 5) the final cumulative disturbance (weighted cumulative DI) image created by combining each $\Delta$ DI image in a weighted sum. 


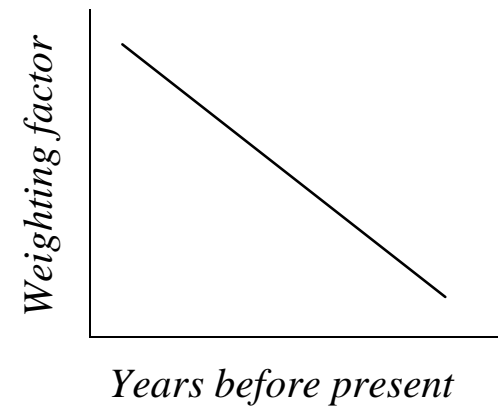

Figure 4: Diagram of the linear weighting scheme used to create the weighted cumulative DI image. The weighting scheme took into account years passed between images and weighted more recent years more heavily than years further from the present. For example, the year 2002 had a weighting factor of fifteen because there were twenty-two years in the analysis and it was seven years before the present.

map (unweighted cumulative DI). While straightforward, this approach could oversimplify the impact of individual years of disturbance, particularly years further from the present. Therefore, I tested my second research hypothesis by applying a linear weighting scheme to the sum, attributing the highest weights to the most recent years and the lowest weights to the earliest years (weighted cumulative DI, Figure 4). I tested the null hypothesis by also using only the most recent $\Delta \mathrm{DI}$ for each study area in my statistical analyses. Though the impacts of disturbance have been shown to decrease over time, no specific timeline of cumulative impacts has yet been established.

While studies of nitrate export in streamwater lend support for my linear weighting scheme, I also acknowledge that disturbance recovery is controlled by multiple factors, including disturbance severity, intensity, frequency, and type (Chapin et al. 2002). All of these factors create a highly variable recovery process that may not be perfectly described by a linear model. Further research on the trajectory of disturbance-related impacts over time may provide additional insights into creating an appropriate weighting scheme for a cumulative disturbance index.

\section{Hyperspectral Imagery Methods}

NASA's ER 2 aircraft, housing the Airborne Visible/Infrared Imaging Spectrometer (AVIRIS) instrument, flew high spectral resolution imagery at $20 \mathrm{~km}$ altitude using two flightlines on July 6 and 14, 2009. The spatial resolution of the imagery is $17-20 \mathrm{~m}$, and the spectral range of $374-2508 \mathrm{~nm}$ at $10-\mathrm{nm}$ intervals covers 224 bands. The flightlines corresponded with field data collection within the study areas during peak summer growing months. A total of four images over the study sites were acquired, two covering SRSF and two covering GRSF. I followed the general methods of McNeil (2006) and Martin et al. (2008) to create canopy N maps from the 2009 AVIRIS data.

Image preprocessing was performed by Aditya Singh at the University of Wisconsin Madison ${ }^{1}$. The five distinct steps involved were the development of an integrated cloud and

\footnotetext{
${ }^{1}$ Aditya Singh performed all AVIRIS preprocessing before delivering the final analysis-ready imagery for use in this project. Unless otherwise referenced, all correction algorithms were written and implemented by Singh. I had no part in performing these steps, and I only comment on his methods in this manuscript to provide background information on the data used in this project.
} 
cloud-shadow mask, cross-track illumination correction, removal of overlapping bands, correction of atmospheric effects and conversion to top-of-canopy (TOC) reflectance, and terrain illumination correction. The cloud detection algorithm took advantage of AVIRIS band 164 $(1897 \mathrm{~nm})$ in which clouds are distinguished from a usually uniform background comprising mostly random noise with values ranging from 0 to 5 (empirically determined). To extract clouds, he first used a $3 \times 3$ filter to reduce the effect of random high values and then thresholded the filtered image to select all values over 5. Cloud-shadows were best detected using a narrow band normalized difference infrared index (NDII $=[\mathrm{B} 43-\mathrm{B} 97] /$ [B43 $-\mathrm{B} 97]$, where: B43 $=753$ $\mathrm{nm}, \mathrm{B} 97=1253 \mathrm{~nm}$ ). After a number of iterations across a number of images, NDII values less than 0.6 were found to be effective in isolating cloud shadows with a fairly high accuracy. The cloud and cloud shadow images were combined and a majority filter was applied to generate a combined cloud and cloud shadow mask.

AVIRIS images often have systematic cross-track illumination effects due to a combination of flight path orientation and relative solar azimuth. These effects are most pronounced when the flight path follows the major cardinal directions (north-south or east-west). In most cases though, the flight path does not strictly conform to cardinal directions and images are differentially illuminated along the image diagonal. Further, cross-track illumination effects are often also band specific. To take into account illumination effects from varying flight path geometries, Singh generated illumination trend surfaces as fits of bilinear models mapping image radiance values to map coordinates. Separate models were estimated for all cloud/shadowmasked pixels of each band. For each band, beta coefficients estimated from the model were applied to unmasked image values to generate illumination trend surfaces. Finally, individual bands were trend-normalized by subtracting the illumination trend surface and adding the image mean to arrive at cross-track illumination corrected bands.

The AVIRIS instrument comprises four sensors with relative spectral responses spanning the wavelengths $365-667 \mathrm{~nm}, 655-1263 \mathrm{~nm}, 1253-1872 \mathrm{~nm}$, and 1866-2496 nm. As a consequence, there are overlaps in wavelengths between consecutive bands ranging from $6 \mathrm{~nm}$ to $12 \mathrm{~nm}$ where the sensitivities of the sensors overlap. As these overlaps could potentially cause problems when correcting for atmospheric effects, Singh dropped all bands from the end of the spectral range for each sensor. In total, seven bands (B33, B34, B97, B98, B160, B161, and B162) were dropped. Atmospheric correction and conversion to at-canopy reflectance of crosstrack illumination corrected images was conducted using ACORN5b ${ }^{\mathrm{TM}}$ software (Atmospheric CORrection Now; Imspec LLC, USA) using mode 1.5 (advanced atmospheric correction for hyperspectral data with spectral fitting for water vapor and vegetation liquid water).

Atmospherically corrected imagery was then corrected for differential illumination effects due to terrain geometry by using the C-factor method (Teillet et al. 1982). Similar to cross-track illumination correction, the model was fit to cloud/shadow masked pixels of each 
(a)
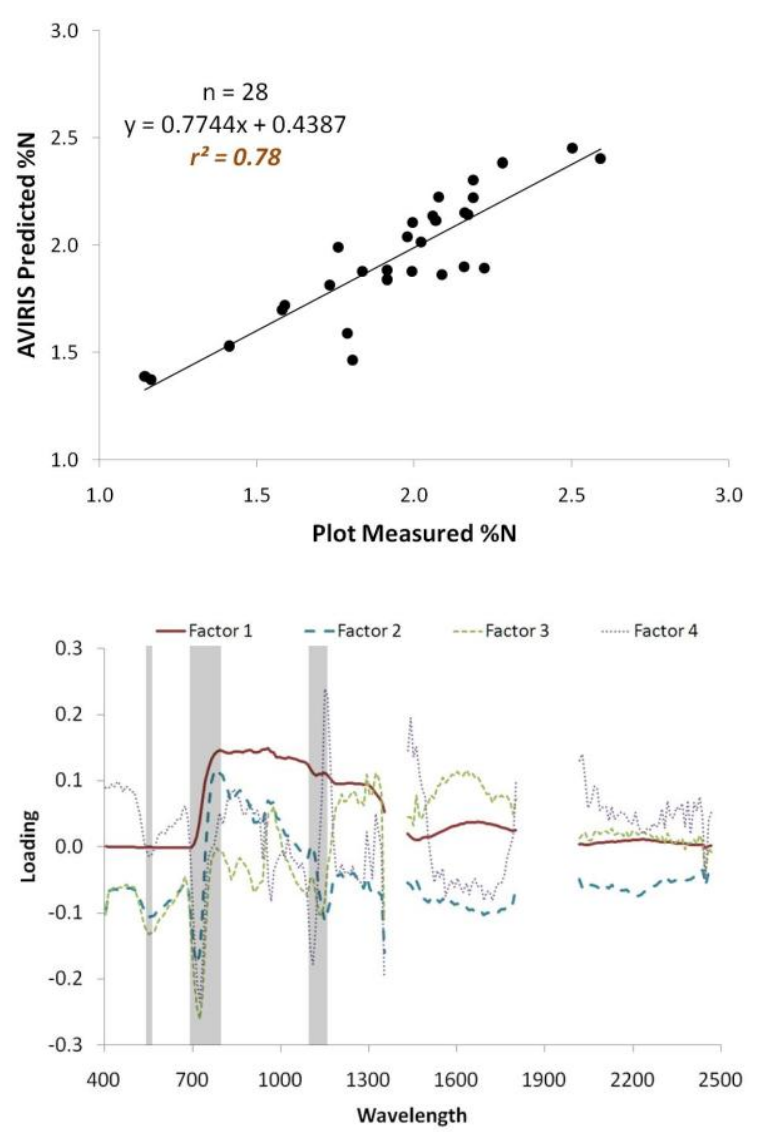

(b)

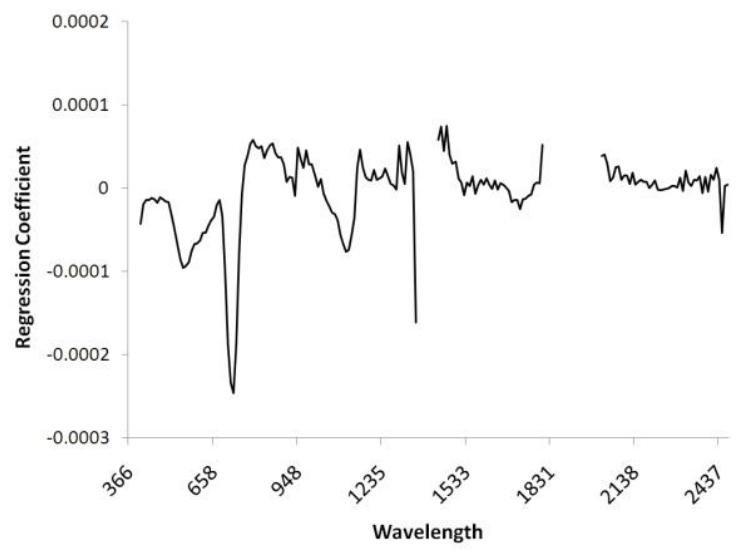

(c)

Figure 5: Results from the PLS regression between plot-measured canopy $\mathrm{N}$ and AVIRIS reflectance values. (a) The relationship between plot-measured canopy $\mathrm{N}$ values and AVIRIS-predicted canopy $\mathrm{N}$ values, (b) the factor loadings, and (c) The PLS regression coefficients used in the creation of the canopy $\mathrm{N}$ maps through 'calcN'. band and the coefficients were applied to the entire (unmasked) image to arrive at terraincorrected reflectance values. The IL (illumination or cosine-i) image was also provided as a separate dataset along with the full AVIRIS data product. After preprocessing, the images were left with 183 bands to be used in the partial least squares regression equation.

I extracted reflectance spectra from the single nearest pixel to each field plot coordinate from both study sites and all four images. I then used partial least squares (PLS) regression to relate field measurements of plot-level canopy $\mathrm{N}$ with the remaining 183 bands of reflectance spectra from the four AVIRIS images (Ollinger and Smith 2005, Smith et al. 2002, 2003, Martin et al. 2008). Some past studies have used the original unsmoothed reflectance values (McNeil et al. 2008, Martin et al. 2008), while others have used first-derivative reflectance data (Townsend et al. 2003). While the first-derivative approach can detect canopy $\mathrm{N}$ using fewer bands, I opted to use the full-spectrum approach to include the full range of spectral information present in the AVIRIS imagery.

To run the PLS regression, I used The Unscrambler (version 9.8, Camo Software, Oslo, Norway). PLS allows for a regression analysis to relate a large number of independent variables to a much smaller number of dependent variables by reducing the independent variables into a specified number of latent factors (very similar to principal components analysis). A rule-ofthumb in choosing the number of latent 
factors is to have a minimum of three samples (i.e. field plots) for each term (factor, coefficient, and intercept) in the model (McNeil 2006). The optimum number of factors was also determined by selecting the model with the minimum predicted residual sum of squares statistic (PRESS) (Townsend et al. 2003). I used four latent factors in my model since I had 28 field plots. Using more than this rule-of-thumb risks over-fitting the model without contributing substantial explanatory power. Canopy $\mathrm{N}$ values obtained using the camera-method and the basal area method showed no significant difference, so I opted to use values derived from the more detailed camera-method in the creation of my AVIRIS canopy $\mathrm{N}$ maps. Both methods accounted for mass-based (LMA) fractional proportional of species in determining the plot value of canopy $\mathrm{N}$. The PLS regression provided me with a set of regression coefficients and loadings for each band (Figure 5).

The PLS regressions produced strong predictive relationships, comparable with calibration relationships produced from previous studies (Smith et al. 2002, Townsend et al. 2003, Martin et al. 2008, Figure 5). My four factor model accounted for about $78 \%$ of the variability in plot-level measured canopy $\mathrm{N}$ and about $63 \%$ of the variability in the AVIRIS reflectance spectra. Root mean square error (RMSE) was also comparable those reported in previous studies, with 0.16 percent $\mathrm{N}$ in the plot-measured canopy $\mathrm{N}$. The latent factors represent weightings in the linear combination of bands, and provide insight into the location of absorption features. The first latent factor accounted for $92 \%$ of the explained variability in the AVIRIS spectra and resembled the general reflectance curve seen in vegetation (Figure 5b). This general reflectance curve represents the albedo signature described by Ollinger et al. (2009), which was found to correlate with canopy $\mathrm{N}$. The remaining factors emphasized absorption features that correspond with important leaf biochemical properties, such as chlorophyll and Ncontaining proteins. These absorption features were found in factor two at $560 \mathrm{~nm}, 1130 \mathrm{~nm}$, and $1350 \mathrm{~nm}$; in factor three at $560 \mathrm{~nm}, 1140 \mathrm{~nm}$, and $2436 \mathrm{~nm}$; and in factor four at $560 \mathrm{~nm}$, $1150 \mathrm{~nm}, 1353 \mathrm{~nm}, 1442 \mathrm{~nm}, 2067 \mathrm{~nm}$, and $2446 \mathrm{~nm}$. There is a large absorption feature evident in all factors located around 680-800 nm, an area known as the "red edge," which is typically used to describe vegetation greenness because it is strongly correlated with chlorophyll content in leaves (Jensen 2007).

The relationship between plot-measured canopy $\mathrm{N}$ and AVIRIS-measured canopy $\mathrm{N}$ was slightly less than unity, indicating that the dynamic range of the AVIRIS-measured canopy $\mathrm{N}$ values was lower than that of the plot-measured canopy $\mathrm{N}$ values (Figure 5a). This could introduce some error into my analysis, considering that the AVIRIS-measurements may be a less sensitive measure of canopy N. In general, SRSF displayed higher canopy N values than GRSF, which could be a result of the differences in species composition. Martin et al. (2008) found that forests with greater diversity in functional types displayed greater error when calibrated using a more generalized equation. While similar species can be found at both of my study areas, the 
greater diversity at SRSF may influence the ability of the model to accurately predict canopy $\mathrm{N}$ across both regions.

I used a compiling program (for IDL (ITT Visual Information Solutions, Boulder, CO) written by Mary Martin of the University of New Hampshire) to apply the regression coefficients to the imagery of GRSF and SRSF. For each pixel, the program summed the product of each band's reflectance and the regression coefficient, producing an estimated canopy $\mathrm{N}$ value for each pixel. Since I had four total images, I ran the program for all four images separately, but using the same coefficients (since all images were used in producing the regression coefficients). Once I had canopy $\mathrm{N}$ maps for each of the four images, I exported them from ENVI and used ArcMap 9.3.1 to mosaic the images of SRSF and GRSF into two images, one covering each study area. I then applied the same non-forest mask used in my Landsat analyses.

\section{Statistical Analyses}

I ran regression analyses to test whether increased cumulative disturbance was predictive of decreased forest canopy cover or increased forest understory cover. I tested several metrics of forest structure, including percent canopy cover, leaf cover, and percent understory cover. In order to account for any slight difference in the plot locations and the image geometry, I ran a low pass filter over the cumulative disturbance images, which averaged pixels in a $3 \times 3$ moving window across the entire image. I used the filtered images to extract pixel values for statistical analysis. Since I used a different number of images to create the cumulative DI maps for each study area, I normalized the values by taking the z-score for use in the regression between both study areas. For comparison, I also tested our canopy cover estimates against the most recent $\Delta \mathrm{DI}$ image for each study area (null sub-hypothesis). This comparison allowed me to address my sub-hypotheses and explore whether cumulative DI was more associated with the additive impacts of disturbance than only the most recent year of imagery.

I compared the means of several dominant species types in my study areas using both field-measured species averages and AVIRIS-measured stand type zones created using the GIS species composition maps (Foster and Townsend 2004). Since not all species were available for a sufficient number of plots, the analysis was limited to four stand types that were commonly found throughout the study areas: Quercus alba (white oak), Quercus rubra (red oak), Pinus strobus (white pine), and Acer saccharum (sugar maple). By controlling for stand type, I hoped to further tease out a disturbance signal in the canopy structure and percent $\mathrm{N}$ data. This standlevel analysis also allowed me to further explore the operational scale at which disturbance influences canopy structure and percent $\mathrm{N}$.

Following same vein as the forest structure analyses, I also ran regression analyses on the plot-level canopy $\mathrm{N}$ data and the cumulative disturbance maps to test my second hypothesis. The hyperspectral imagery provided a unique opportunity to assess the relationship between canopy 
$\mathrm{N}$ and cumulative disturbance at broader spatial scales, so I also performed this analysis at the stand-scale and watershed-scale. 


\section{RESULTS}

\section{Cumulative Disturbance Index}

The unweighted cumulative DI displayed values ranging from 2.00 to 64.26 at GRSF and from 0.8 to 57.1 at SRSF. The weighted cumulative DI displayed values ranging from 22.65 to 1194.96 at GRSF and from 9.2 to 1287.3 at SRSF. The most recent $\triangle \mathrm{DI}$ images displayed values ranging from 0 to 26.95 at GRSF and from 0 to 19.78 at SRSF. These values represent relative disturbance intensities based on the two sums of the individual change maps (unweighted and weighted cumulative DI) and intensities based on a single, recent year of disturbance (the most recent $\Delta \mathrm{DI}$ image for each study area), where lower values are less disturbed and higher values are more disturbed. Note that all analyses were performed using zscore normalized data. Qualitatively, past disturbances, such as the large defoliation at GRSF in 1991, appeared more prominent in the unweighted cumulative DI image, while recent disturbances, such as the massive defoliations at SRSF in 2007, appeared more prominent in the weighted cumulative DI image.

Healey et al. (2005) quantitatively assessed the accuracy of DI by creating 50 iterations of a comprehensive error matrix comparing DI with manually digitized reference maps. Subsequent studies have since used the DI (Eshleman et al. 2009, Hais et al. 2009) to map disturbance in both conifer forests and eastern deciduous forests. To further validate the DI, I performed a qualitative accuracy assessment using GIS polygons of the previously identified disturbance classes. Within GIS polygons there was a great deal of variability, but each version of the cumulative DI was able to identify trends in clear-cut harvests and gyspy moth defoliation.

Table 4: Results from the regressions $\left(r^{2}\right)$ between forest structure variables and the different versions of DI. Non-significant results are indicated by ns. Results significant at the 0.01 level are displayed in bold. Results significant to the 0.001 level are displayed in bold and italics.

\begin{tabular}{|l|l|l|l|l|}
\cline { 3 - 5 } \multicolumn{2}{c|}{} & GRSF & SRSF & Both Forests \\
\hline \multirow{3}{*}{$\%$ Canopy Cover } & Unweighted DI & $\mathbf{0 . 4 3}$ & $\mathrm{ns}$ & $\mathbf{0 . 2 7}$ \\
\cline { 2 - 5 } & Weighted DI & $\mathbf{0 . 5 2}$ & $\mathbf{0 . 4 8}$ & $\mathbf{0 . 3 0}$ \\
\cline { 2 - 5 } & Most recent DDI & $\mathrm{ns}$ & $\mathrm{ns}$ & $\mathrm{ns}$ \\
\hline \multirow{3}{*}{$\%$ Leaf Cover } & Unweighted DI & $\mathrm{ns}$ & $\mathrm{ns}$ & $\mathrm{ns}$ \\
\cline { 2 - 5 } & Weighted DI & $\mathrm{ns}$ & $\mathrm{ns}$ & $\mathrm{ns}$ \\
\cline { 2 - 5 } & Most recent DDI & $\mathrm{ns}$ & $\mathrm{ns}$ & $\mathrm{ns}$ \\
\hline \multirow{3}{*}{ Understory } & Unweighted DI & $\mathrm{ns}$ & $\mathrm{ns}$ & $\mathrm{ns}$ \\
\cline { 2 - 5 } & Weighted DI & $\mathrm{ns}$ & $\mathrm{ns}$ & $\mathrm{ns}$ \\
\cline { 2 - 5 } & Most recent $\Delta D I$ & $\mathrm{~ns}$ & $\mathrm{~ns}$ & $\mathrm{~ns}$ \\
\hline
\end{tabular}


Variability within defoliated classes was particular high, which could be attributed to the more variable nature of this type of disturbance. Harvested areas tend to be located in relatively discrete areas defined by forest management practices, while defoliations occur in varying intensities across the landscape.

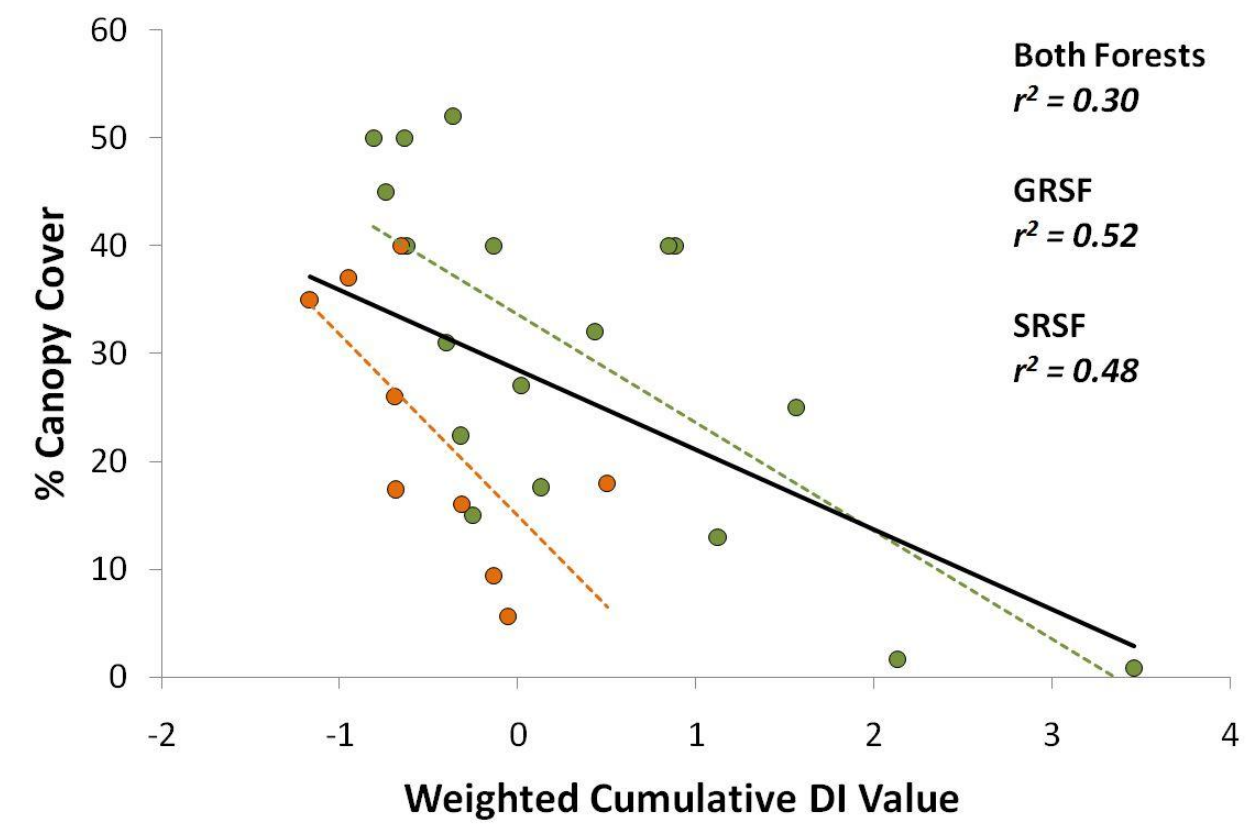

(a)

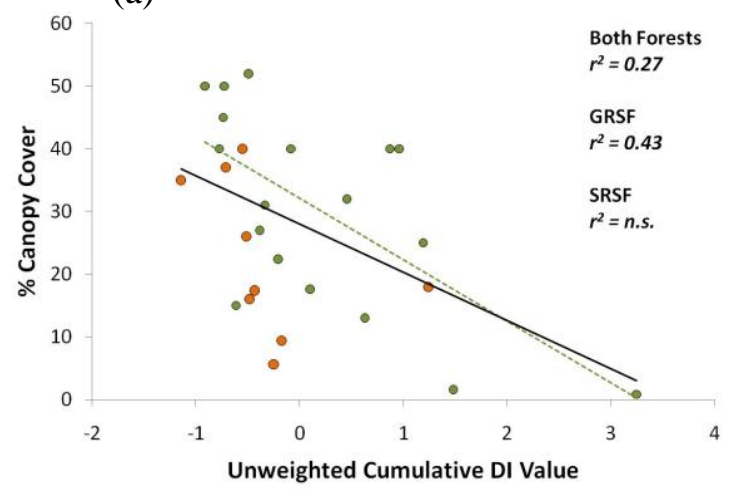

(b)
- Savage River State Forest

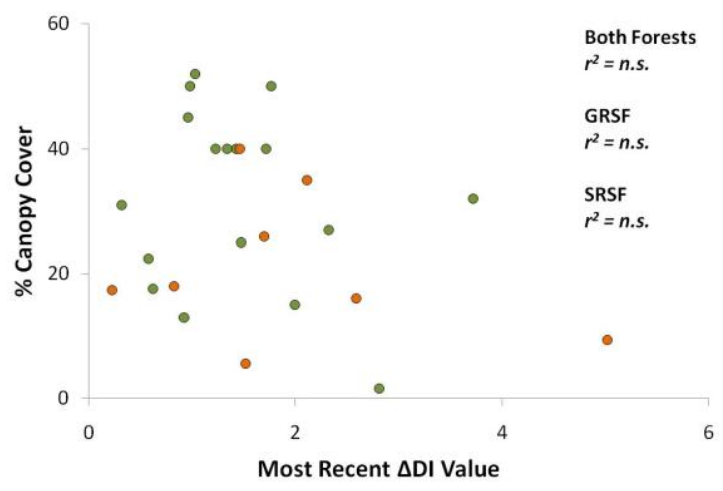

(c)

Figure 6: The relationship between \% canopy cover and (a) weighted cumulative DI, (b) unweighted cumulative DI, and (c) the most recent $\Delta$ DI. The weighted cumulative DI produced the strongest relationship with \% canopy cover. Results displayed are significant to the 0.01 level. N.S. refers to nonsignificant results. All DI data is z-score normalized. 


\section{Forest Structure}

The results from my regression analyses suggest that cumulative disturbance has a strong effect on percent canopy cover, but a minimal, non-significant effect on percent understory cover and percent leaf cover (Figure 6, Table 4). Canopy cover produced the most significant relationships with both cumulative DI maps, but interestingly, did not produce any significant relationships with the most recent $\Delta \mathrm{DI}$ images, indicating that percent canopy cover may be a product of the additive impacts of past and present disturbances together, and not indicative of current disturbance status. While the unweighted cumulative DI did produce significant relationships at GRSF, the weighting scheme tightened the model at both forests, suggesting that the linear weighting model captures a greater portion of the disturbance dynamics.

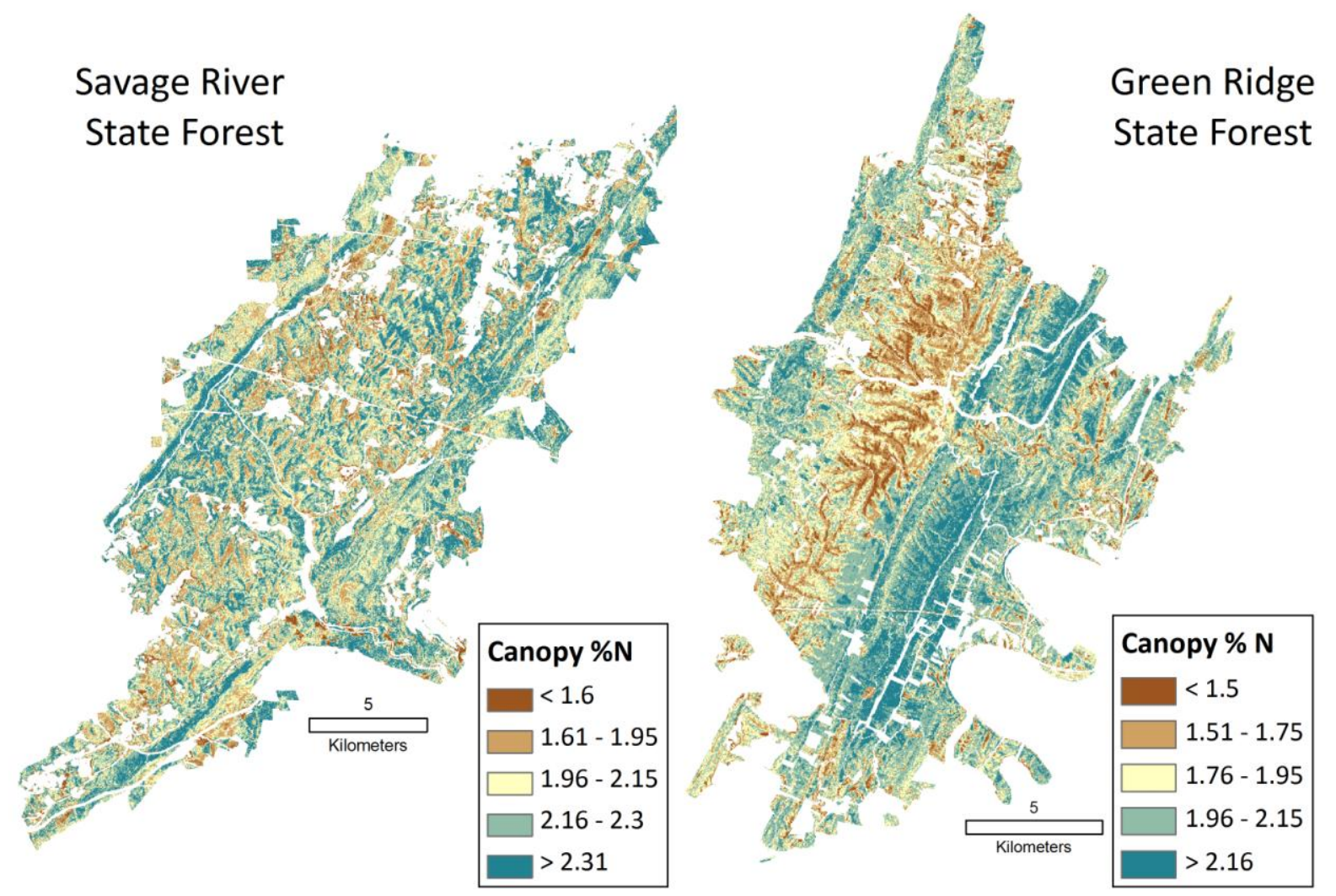

Figure 7: AVIRIS-derived canopy N maps for both study areas. 


\section{Foliar and Canopy N}

Using the canopy $\mathrm{N}$ maps created from the AVIRIS imagery (Figure 7) in combination with the existing maps of species composition, I extracted mean values of the canopy $\mathrm{N}$ status of several dominant species types within each study area (Figure 8). These values follow expected trends of foliar $\mathrm{N}$ by functional types. For example, needleleaf pine species consistently display lower mean values than broadleaf oak and maple species. The AVIRIS imagery detected higher values for sugar maple and lower values for white oak than I measured in my field data. Pine values were also somewhat different, but I used only white pine for the plot-measured canopy percent $\mathrm{N}$ values, while I used several pine species (including $P$. resinosa, $P$. virginiana, $P$. ridiga, and $P$. strobus) for the AVIRIS-measured canopy percent $\mathrm{N}$ values, so these differences could be related to species differences.

Regression analyses focusing on the plot-level canopy $\mathrm{N}$ values displayed no significant relationship with cumulative disturbance $\left(\mathrm{r}^{2}=0.04,0.06\right.$, and 0.06 , for unweighted cumulative DI, weighted cumulative DI, and most recent $\Delta \mathrm{DI}$, respectively, Table 5). These results were consistent with the results from an earlier pilot project using canopy $\mathrm{N}$ collected in 2001, suggesting that a plot-based scale may not be appropriate for understanding the relationship of canopy $\mathrm{N}$ status to cumulative disturbance. The AVIRIS-derived canopy $\mathrm{N}$ maps made it possible for me to examine the effects of disturbance on canopy $\mathrm{N}$ at the stand- and watershed-

(a)

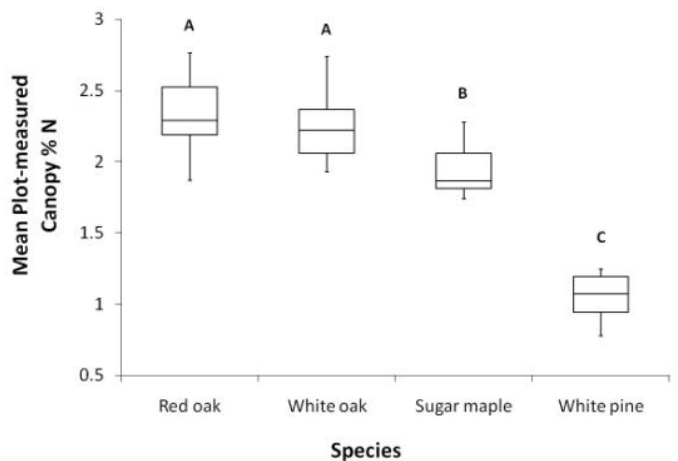

Figure 8: Species means derived from (a) plot-measured canopy $\% \mathrm{~N}$ values and (b) AVIRIS-derived canopy N values aggregated by GIS species composition maps (Foster and Townsend 2004). Levels not connected by the same letter are significantly different. 
Table 5: Results from the regressions $\left(r^{2}\right)$ between canopy $\% \mathrm{~N}$ values at the plot-, stand-, and watershed-scale and the different versions of DI. Non-significant results are indicated by ns. Results significant to the 0.05 level are displaying in plain text. Results significant at the 0.01 level are displayed in bold. Results significant to the 0.001 level are displayed in bold and italics. No data is indicated by --.

\begin{tabular}{|c|c|c|c|c|}
\hline & & GRSF & SRSF & Both Forests \\
\hline \multirow{3}{*}{ Plot-Level } & Unweighted DI & ns & $\mathrm{ns}$ & ns \\
\hline & Weighted DI & ns & ns & ns \\
\hline & $\Delta D I$ & 0.30 & ns & $\mathrm{ns}$ \\
\hline \multirow{3}{*}{$\begin{array}{l}\text { Red oak } \\
\text { Stand-Level }\end{array}$} & Unweighted DI & ns & ns & $\mathrm{ns}$ \\
\hline & Weighted DI & ns & 0.22 & 0.13 \\
\hline & $\Delta D I$ & ns & 0.12 & 0.12 \\
\hline \multirow{3}{*}{$\begin{array}{l}\text { White oak } \\
\text { Stand-Level }\end{array}$} & Unweighted DI & ns & ns & 0.09 \\
\hline & Weighted DI & ns & ns & 0.07 \\
\hline & $\Delta D I$ & 0.14 & ns & ns \\
\hline \multirow{3}{*}{$\begin{array}{l}\text { Sugar maple } \\
\text { Stand-Level }\end{array}$} & Unweighted DI & -- & 0.29 & -- \\
\hline & Weighted DI & -- & 0.31 & -- \\
\hline & $\Delta D I$ & -- & ns & -- \\
\hline \multirow{3}{*}{$\begin{array}{l}\text { Pine } \\
\text { Stand-Level }\end{array}$} & Unweighted DI & ns & 0.20 & 0.20 \\
\hline & Weighted DI & ns & 0.16 & 0.14 \\
\hline & $\Delta D I$ & ns & ns & ns \\
\hline \multirow{3}{*}{ Watershed-Level } & Unweighted DI & ns & 0.21 & 0.09 \\
\hline & Weighted DI & 0.21 & 0.45 & 0.20 \\
\hline & $\Delta D I$ & $\mathrm{~ns}$ & 0.18 & ns \\
\hline
\end{tabular}

scale, which displayed much stronger relationships than the plot-level canopy $\mathrm{N}$ data, particularly at SRSF (Table 5).

Moving up in scale, I also ran regressions between canopy $\mathrm{N}$ and cumulative disturbance at the stand-scale using species zones (Table 5). These species zones were created using a GIS layer of species composition created by Foster and Townsend (2004). I used the AVIRISderived canopy $\mathrm{N}$ maps to extract mean values from four dominant species types found within my two study areas, including white oak, red oak, pine, and sugar maple. I ran regressions using these mean canopy percent $\mathrm{N}$ values and mean values from unweighted cumulative DI, weighted cumulative DI, and the most recent $\Delta \mathrm{DI}$. The response varied between species (Table 5), suggesting that one single weighting strategy or even a single method of mapping cumulative disturbance may not be adequate to describe the successional strategies of differing species types. For all species except red oak, the cumulative DI (both unweighted and weighted) produced the strongest relationships with canopy N. Within the unweighted cumulative DI, pine 
and sugar maple displayed the strongest relationships, while the oak species displayed virtually no relationship. Within the weighted cumulative DI, sugar maple displayed the strongest relationship, while red oak and pine displayed moderate relationships. When considering only the most recent $\Delta \mathrm{DI}$, the oak species displayed moderate relationships, while pine and sugar maple displayed almost no relationship.

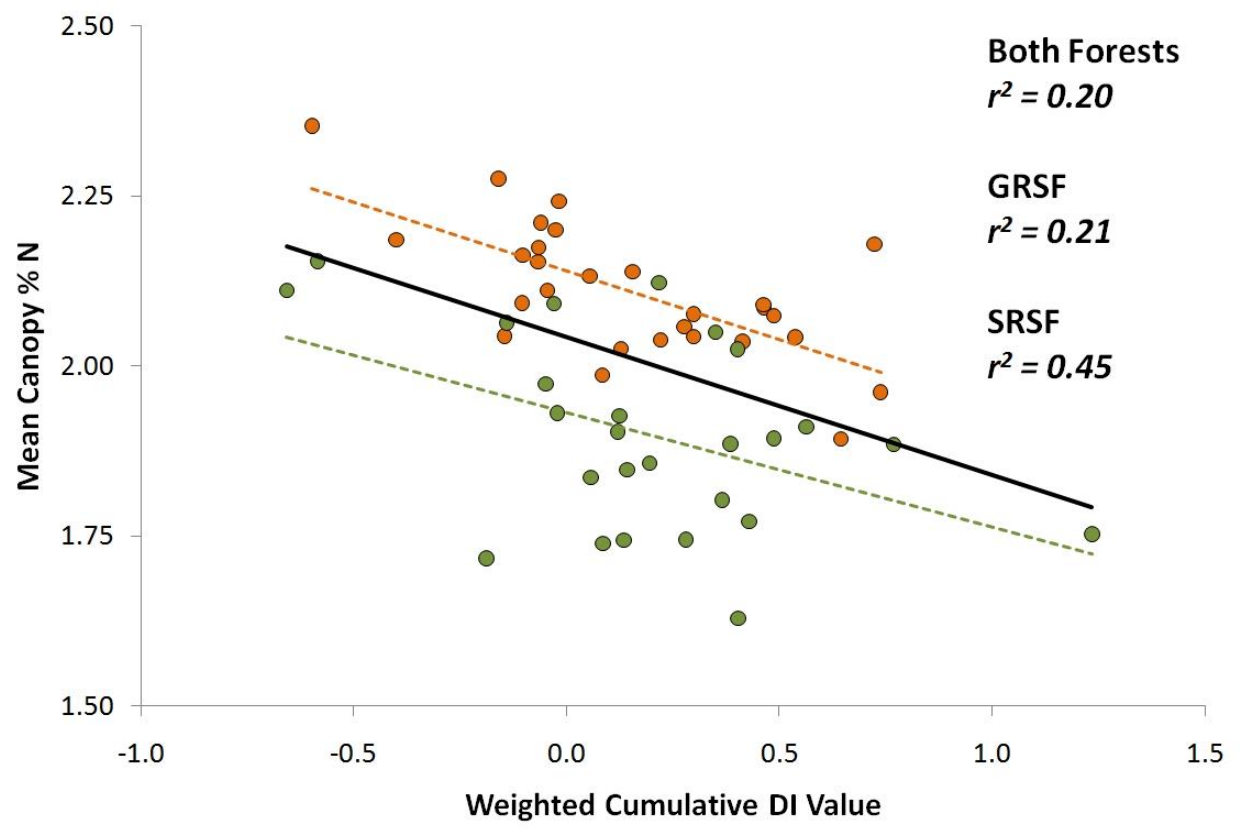

(a)

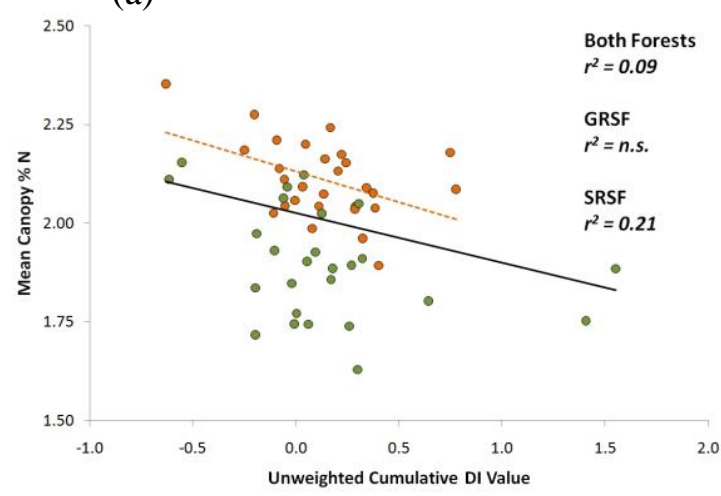

(b)

- Savage River State Forest - Green Ridge State Forest

(c)

- Green Ridge State Forest

Figure 9: The watershed-scale relationship between $\%$ canopy $\mathrm{N}$ and (a) weighted cumulative DI, (b) unweighted cumulative DI, and (c) the most recent $\Delta$ DI. The weighted cumulative DI produced the strongest relationship with \% canopy N. All displayed regression lines are significant at the 0.05 level. All DI data is z-score normalized. 
The final and broadest scale of analysis I used in assessing the relationship between canopy $\mathrm{N}$ and cumulative disturbance was the watershed scale. I used fifty-four watershed boundaries used in a previous study by Townsend et al. (2004). Keith Eshleman from the University of Maryland Center for Environmental Science Appalachian Lab in Frostburg, Maryland used these watersheds for stream water nitrate sampling during 2007. At the watershed-scale, the relationship between canopy percent $\mathrm{N}$ and cumulative disturbance varied by both study area and method of estimating cumulative disturbance (Figure 9, Table 5). The strongest relationship occurred at SRSF between canopy percent $\mathrm{N}$ and the weighted cumulative $\mathrm{DI}$, indicating that canopy $\mathrm{N}$ at SRSF may be controlled in large part by disturbance. Using the weighted cumulative DI to assess canopy N at GRSF produced a less strong, yet still significant, relationship. 


\section{DISCUSSION}

\section{Cumulative Disturbance Index}

My study was designed to assess the utility of using remote sensing imagery to map cumulative forest disturbance and to examine the relationship between cumulative disturbance and forest structure and chemistry. The cumulative DI (particularly the weighted cumulative DI) produced relatively strong relationships with percent canopy cover at the plot-level and with canopy percent $\mathrm{N}$ at the stand- and watershed-level. The strength of these results combined with previous research on the additive nature of disturbance (Goodale and Aber 2001, Latty et al. 2004, Foster et al. 2003) provides evidence for the utility of a cumulative method for assessing disturbance impacts on forest functioning. The cumulative disturbance index I have proposed represents an innovative method for reconstructing a forest's past disturbance history without the need for exhaustive field data collection for multiple temporal periods, which is often unavailable or inconsistent. By using a linear weighting scheme, the model acknowledged years passed between image dates and accounted for them in the weighting factors, which can be important because anniversary images are often not available due to cloud cover or other issues.

Since the cumulative disturbance index includes imagery from 14 dates across over 20

years of history, performing an accuracy assessment was somewhat challenging. My decision to perform a qualitative accuracy assessment alone, rather than repeating the quantitative assessment of Healey et al. (2005) is based on several major reasons. First, this method assumes that the 'truth' data, in this case the GIS polygon data, is accurate and complete. Secondly, it assumes that the scale of data collection is consistent and comparable to my cumulative DI images. These assumptions are almost certainly violated in this analysis. For example, a visual comparison of forest harvest GIS data reveals a great deal of variability within individual GIS polygons (Figure 10). While this variability may limit the utility of using GIS data for quantitative accuracy assessment, it contributes to the depth of information present in the cumulative disturbance index.

Gypsy moth defoliation GIS data was originally created by using sketch maps of aerial imagery flown over most of the northeastern and mid-Atlantic regions of the United States. While these data provide a valuable resource covering broad-scale defoliation patterns, they were not intended, nor are they capable, of mapping fine-scale variability. Thus, the problem of scale and completeness of the 'truth' data may have a potentially large affect on a quantitative accuracy assessment of the cumulative disturbance index. The harvest data was also collected by two different state forest offices with no documentation on the scale or accuracy of the data. The data for GRSF included attribute data on the year of harvest, but the SRSF data did not include this information. I suggest that my cumulative DI maps may actually be more accurate and complete than the 'truth' data on which they can be assessed. 
One major limitation of the cumulative DI approach is that not every year provides a cloud-free image, and in some instances, missing years may be critical in reconstructing a site's disturbance history. For example, I ran a test analysis at GRSF that assessed the importance of individual years of disturbance data. The image for 22 August 2000 over GRSF contained more clouds than most of the other images used in this analysis, so I created one cumulative DI that included this image and one that did not. GRSF experienced a major gypsy moth defoliation during this year. The differences between my results were striking for this test analysis. The relationship between the weighted cumulative DI and canopy percent $\mathrm{N}$ at GRSF went from being a non-significant $r^{2}$ of 0.10 to a significant $r^{2}$ of 0.21 . The implications given these vast differences in the strength of the observed relationship based on the inclusion or omission of just a single year of imagery are that the effectiveness of cumulative DI is highly contingent on the availability of data. The relationships I observed in this analysis were strong, even though some

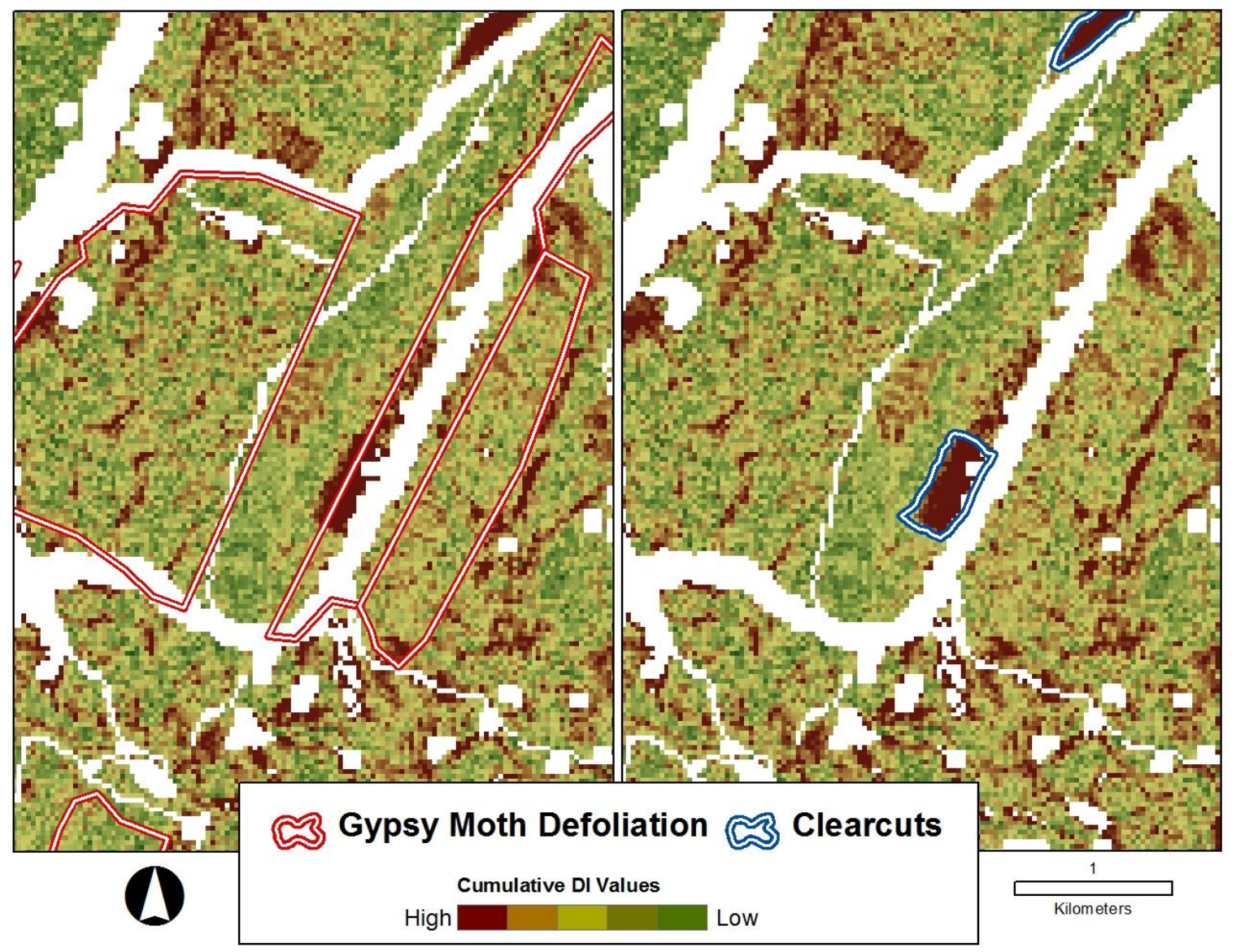

Figure 10: Qualitative assessment of the accuracy of cumulative DI compared with GIS polygon data describing gypsy moth defoliation and recent clearcut (since 2000) disturbances within GRSF. 
years of imagery could not be included due to persistent cloud cover, so it is very possible that the relationship could become even stronger with the inclusion of a full and complete set of input imagery.

One way around this limitation is to come up with an effective, automated cloud and cloud-shadow removal algorithm. While this could increase the potential number of images to be included in the cumulative DI, it may also cause more problems because in order to accurately sum the change maps, a single, uniform mask must be applied to all images in the stack so that cumulative values truly represent the accumulated disturbance across all years. If cloud-cover is too extensive and must be added to a single, overarching mask, then one could risk masking out too much of the analysis area and losing valuable spatial information. Potential ways around this limitation include the development of an interpolation algorithm to create probable values in cloud-affected areas or, perhaps, finding some way of accounting for missing years within the weighting scheme. Either way, the issue presents a dilemma for users surrounding the question of whether it is better to have a more complete set of temporal data or a more complete set of spatial data.

The use of a $\mathrm{DI}_{\min }$ image for comparison represents a novel method in calculating forest disturbance across multiple dates of imagery, though the use of $\Delta \mathrm{DI}$ calculated from previous image years is not a new concept. Eshleman et al. (2009) used $\Delta$ DI and synoptic water quality data to identify forest disturbance in a single watershed within Green Ridge State Forest. They found a strong linear relationship between $\Delta \mathrm{DI}$ value and streamwater export of nitrate, providing validation and lending support for the use of $\Delta \mathrm{DI}$ as a reliable indicator of disturbance intensity across broad scales. The incorporation of the $\mathrm{DI}_{\min }$ alleviates the need to find a suitable reference year for comparison in change and disturbance detection. Though the image is essentially a multitemporal composite, it provides an otherwise unattainable reference point for quantifying relative disturbance and change over a large temporal period.

While DI has indeed been shown to reliably map disturbance intensity, there may still be other indices that provide a comparable or perhaps better measure of cumulative disturbance. Some recent work examining the NDMI and the related ratio of band 5 to band 4 (Jin and Sadar 2005, Healey et al. 2006, de Beurs and Townsend 2008) suggest that these indices may also be appropriate for mapping disturbance and may be used in future studies as a comparison with the DI. Future research on the use of cumulative disturbance maps to assess forest structure and function may benefit from testing other indices that have shown promise in detecting disturbance types.

Future studies that wish to make use of the cumulative disturbance index may also benefit from exploring other methods of weighting, such as exponential or other nonlinear weighting schemes. The independent variable under consideration may also dictate the weighting scheme selected. For example, forest structure and biomass often recover at a more rapid pace than nutrient availability (Likens et al. 1978, Vitousek and Reiners 1975, Bormann and Likens 1979). 
While much work has been done on disturbance mapping and disturbance dynamics, relatively little is known about the temporal trajectory of recovery. Thus, further exploratory work on such a trajectory would enhance the accuracy and value of the cumulative disturbance index. For example, studies conducted by Kennedy et al. (2007) and Huang et al. (2009) utilized dense stacks of Landsat imagery to produce temporal trajectories of forest disturbance using two different algorithms. These studies covered approximately the same range of years as our study, without considering the additive properties of cumulative disturbance. Future work on disturbance dynamics could make use of the temporal trajectory information provided by such studies in the calculation of more powerful cumulative disturbance indices.

\section{Cumulative Disturbance and Forest Structure}

In general, my results supported the hypothesis that increased cumulative disturbance causes a decrease in forest canopy cover, but did not support an effect on understory or leaf cover. The measures of canopy cover, leaf cover and understory cover represent heightindependent estimates that stand as a relative assessment of the forest structure within individual plots. Using leaf cover measurements derived from a densitometer and understory cover estimates likely failed to relate with disturbance because of simple differences in species composition and successional rates between understory and overstory species within the two forests. In general, percent leaf cover and percent understory cover may recover too quickly to adequately describe a forest's disturbance history. These variables may also just not be powerful enough to carry a disturbance signal across multiple years of additive disturbance impacts.

Within each study site individually, there was a strong relationship between the cumulative DI images and the percent canopy cover (Figure 6, Table 4), but the nature of the relationships suggests that there are differences between sites. When combined in a single regression, the relationship was less strong overall, and a t-test indicated significant differences between site means $(\mathrm{p}=0.003)$. The significant differences in the trend between the study areas suggest that between-site differences may be quite large and have the potential to weaken the relationship between cumulative disturbance and forest structure when combining too many sites across different environmental gradients. In my study, these within-site differences are likely due to the differing species compositions of the two study sites. For example, GRSF is composed largely of oak species, while SRSF has oaks as well as an abundance of northern hardwood and pine forest types. The diversity of species at SRSF likely produces differing successional strategies, and therefore, a relationship of similar strength between cumulative DI and canopy cover, but differing slope and intercept within the regression equation. For this reason, it may be appropriate to include species type as a secondary independent variable in a multiple regression equation for analyses designed to assess multiple forest types. 
The strong relationship between canopy cover and cumulative disturbance contains striking implications about the continued ability of a forest to sequester carbon after multiple years of compounding disturbance events. Maps of cumulative disturbance may serve as potential inputs into models of carbon sequestration and forest productivity, providing insight into historical properties of a forest that may otherwise be impossible to include without extensive fieldwork or historical records. Kennedy et al. (2007) suggest that consideration for the temporal nature of disturbance using satellite imagery provides depth to change studies and represents an opportunity to create more inclusive and accurate algorithms of forest change dynamics. The cumulative disturbance index represents an accessible and relatively simple to interpret method for modeling disturbance dynamics across a landscape. An interesting and exciting result from this study is the relative lack of explanatory power provided by using the most recent $\Delta \mathrm{DI}$ image compared with using the cumulative disturbance index. The spatial variability in forest structure is affected by long-term successional dynamics, and studies assessing drivers of forest structure variability should consider the additive effects of many previous disturbances.

\section{Mapping Canopy N}

The species and stand means of canopy $\mathrm{N}$ (Figure 8) provide some insight into the differences between assessing canopy $\mathrm{N}$ at different scales. The AVIRIS imagery detected higher values for sugar maple and lower values for white oak than I measured in my field data. There are a number of potential reasons for this difference. First, and most likely, the variation may be attributed to the difference in the scale and location of my field measurements. My field sampling may not have been representative of all species found within the study areas. Secondly, the differences may be related to the lesser dynamic range of the AVIRIS-measured canopy $\mathrm{N}$ values. In this case, my field data may have actually captured more of the range in $\mathrm{N}$ values than the AVIRIS-derived maps.

As a point of comparison, I examined the canopy N maps created at GRSF in 2001 (Townsend et al. 2003). In general, Townsend's maps displayed higher values of canopy $\mathrm{N}$ across the landscape. A very probable explanation for this discrepancy lies in differences between sampling strategies. Townsend heavily sampled a wide variety of broadleaf species for use in calibration and validation. My inclusion of a substantial number of conifer species likely increased the range of values used in the calibration and validation model by adding to the lower end of the range.

Since the detection of biogeochemical properties using imaging spectroscopy in ecosystems is still evolving, extensive fieldwork is required for calibration and validation. Martin et al. (2008) proposed a generalizable method for detecting canopy $\mathrm{N}$ across a range of forest ecosystems, which may eventually eliminate the need for time-consuming and potentially 
logistically difficult fieldwork. My results lend support for the proposed generalizable method, but also confirm that more research and calibration data may still be needed before this idea can be fully realized. Results from my study supported the idea of using a more generalized equation. As I developed the PLS regressions used to produce the regression coefficients, I tested separate calibrations by study area and a more general calibration including field measurements from both study areas together. I expected the site-specific calibrations to produce stronger relationships in the PLS regression, yet results produced using both study areas together were stronger. Perhaps my study areas were similar enough that including a greater number of measured samples could only improve the model. The inverse could also be true, in that the inclusion of more sampled measurements may have captured variability missed in my field sampling at one or the other study area.

\section{Cumulative Disturbance and Canopy $\mathbf{N}$}

Perhaps one of the major surprises of this project was the total lack of a relationship between plot-level canopy $\mathrm{N}$ and cumulative disturbance history. The most likely explanation is simply that the disturbance signal is masked by variability in canopy $\mathrm{N}$ caused by species composition at this scale of analysis (McNeil et al. 2008). In addition to species composition, other environmental factors, such as $\mathrm{N}$ deposition, may be influencing the variability in canopy $\mathrm{N}$. Foliar $\mathrm{N}$ is determined by a combination of plant functional traits, and environmental and human impacts on the environment (disturbance) (McNeil 2008), so some of the unexplained variance from my study may result from these additional factors.

A simple visual inspection indicated that different factors were driving the spatial patterns of canopy $\mathrm{N}$ to differing degrees in each forest (Figure 7). SRSF has been affected by several recent years of intense and widespread gypsy moth defoliation, and the relationship between cumulative disturbance and canopy $\mathrm{N}$ at the watershed scale reflects the idea that disturbance is the dominant control on canopy $\mathrm{N}$ in SRSF. The relationship was less strong at GRSF, indicating that canopy $\mathrm{N}$ may be controlled predominantly by some other factor (i.e. species composition), but may still be influenced by past disturbances. At GRSF, species composition appears to exert a more dominant control over the spatial distribution of canopy N. For example, low values of canopy $\mathrm{N}$ appear to follow the low-lying band of white oak stands found in GRSF. The detailed species composition maps provided by Foster et al. (2003) served as an input into a combined GIS and statistical analysis of the relationship between species and canopy $\mathrm{N}$ across both study areas. The stand-level analyses produced mixed results on the relationship between canopy percent $\mathrm{N}$ and cumulative DI. These results could allude to a number of processes. For example, oaks were most affected by gypsy moth defoliations in recent years, which may explain the stronger relationship between canopy percent $\mathrm{N}$ and the most recent $\Delta \mathrm{DI}$ images. Furthermore, the strong relationships seen within sugar maple may be 
suggestive of increased $\mathrm{N}$ limitation following cumulative disturbance events. While sugar maple is typically not heavily affected by insect defoliation, instances of widespread defoliation events seen in certain years may cause declines in growth (Luzadis and Gossett 1996).

In almost all cases, the general trend followed my hypothesis of decreasing canopy percent $\mathrm{N}$ with increasing cumulative disturbance with the exception of white oak. Interestingly, white oak was the most heavily affected by gypsy moth defoliation, and the slight, nonsignificant positive relationship observed may be indicative of recovery from disturbance, particularly within GRSF, where the last major defoliation was ten years ago in 2000. In almost all cases, relationships at SRSF were still stronger than those at GRSF. Given the complexity of running separate analyses for each stand type, quantitative measures of forest functional type may provide a more useful alternative to stand-level analyses. A continuous variable of forest functional type could be incorporated as a secondary variable in a multiple regression equation assessing the relationship between canopy percent $\mathrm{N}$ and cumulative DI, perhaps improving the clarity of these results.

Overall, my results lend strong support for my original hypothesis on the relationship of cumulative disturbance and canopy $\mathrm{N}$. While the unweighted cumulative DI produced significant results at SRSF and at the two study sites together, the weighted model ultimately improved the relationship by incorporating the strengths of an additive approach with the acknowledgement that more recent years still exert a stronger control over the current canopy $\mathrm{N}$ status of a forest. Indeed, I have shown that finer-scale field observations of the lasting influence of disturbance on N status (Goodale and Aber 2001, Latty et al. 2004, Foster et al. 2003) can be extended to a broader observational scale using remotely sensed imagery. This approach may also lend itself to future studies on other biogeochemical processes that may be affected by the accumulating affects of disturbance across multiple years. 


\section{CONCLUSIONS}

Overall, my results lend strong support for my two original hypotheses on the relationship of cumulative disturbance to canopy $\mathrm{N}$ and forest structure. An increase in cumulative disturbance was associated with a subsequent decrease in canopy $\mathrm{N}$ and forest canopy cover. Moreover, my sub-hypotheses provided valuable insights into the nature of disturbance as it accumulates over time. The weighted cumulative DI consistently produced the strongest relationships among my three versions of DI with both canopy $\mathrm{N}$ and forest canopy cover, suggesting that past disturbances do diminish over time but still influence the current condition of a forest. Using only the most current $\Delta \mathrm{DI}$ maps consistently produced the weakest relationships, suggesting that current imagery alone may not be adequate to describe the disturbance legacies present in eastern forests. The ability to accurately map cumulative disturbance represents a powerful step towards understanding the impact of disturbance on forest processes and functions. My exploration of scale in this project also proved useful in identifying the operational scale of disturbance impacts on canopy $\mathrm{N}$ and forest structure. Plot- and standscale analyses produced weak, inconclusive results, while the watershed-scale analyses proved much more useful for identifying disturbance impacts on canopy $\mathrm{N}$. The ability to observe and analyze important ecosystem processes at broad spatial scales represents an invaluable opportunity to better understand how forests operate within a broader context. For example, the incorporation of cumulative DI into hydrological models has the potential to generate more accurate predictions of forest nutrient export to large drainage basins, such as the Chesapeake Bay. 


\section{BIBLIOGRAPHY}

Aber, J.D. 1979. A method for estimating foliage-height profiles in broad-leaved forests. The Journal of Ecology 67:35-40.

Asner, G.P. 1998. Biophysical and biochemical sources of variability in canopy reflectance. Remote Sensing of Environment 64:234-253.

Beck, D. E. and R. M. Hooper. 1986. Development of a Southern Appalachian hardwood stand after clearcutting. Southern Journal of Appalachian. Forestry 10:168-172.

Bormann, F.H. and G.E. Likens. 1979. Pattern and Process in a Forested Ecosystem: Disturbance, Development, and the Steady State Based on the Hubbard Brook Ecosystem Study. Springer-Verlag, New York.

Cambell, R.W. and R.J. Sloan. 1977. Forest stand responses to defoliation by the gypsy moth. Washington (DC): Society of American Foresters.

Cao, C. and N.S.-N. Lam. 1997. Understanding the scale and resolution effects in remote sensing and GIS. Pages 57-72 in: Quattrochi, D.A. and M.F. Goodchild, editors. Scale in remote sensing and GIS. Lewis Publishers, Boca Raton.

Chandler, G., B.L. Markham, and D.L. Helder. 2009. Summary of current radiometric calibration coefficients for Landsat MSS, TM, ETM+, and EO-1 ALI sensors. Remote Sensing of Environment 113:893-903.

Chapin III, F.S., P.A. Matson, and H.A. Mooney. 2002. Principles of Terrestrial Ecosystem Ecology. Springer-Verlag, New York.

Chapman, S.K., J.A. Langley, S.C. Hart, and G.W. Koch. 2006. Plants actively control nitrogen cycling: uncorking the microbial bottleneck. New Phytologist 169:27-34.

Chastain Jr., R.A., W.S. Currie, and P.A. Townsend. 2006. Carbon sequestration and nutrient cycling implications of the evergreen understory layer in Appalachian forests. Forest Ecology and Management 231:63-77.

Chavez, P. 1996. Image-based atmospheric corrections - revisited and improved. Photogrammetric Engineering and Remote Sensing 62:1025-1036.

Collins, J.B. and C.E. Woodcock. 1996. An assessment of several linear change detection techniques for mapping forest mortality using multitemporal Landsat TM data. Remote Sensing of Environment 56:66-77.

Crist, E.P. and R.C. Cicone. 1984. A Physically-Based Transformation of Thematic Mapper Data--The TM Tasseled Cap. IEEE Transactions on Geoscience and Remote Sensing 22:256-263.

Crist, E.P. and R.J. Kauth. 1986. The Tasseled Cap de-mystified. Photogrammetric Engineering and Remote Sensing 52:81-86.

Curran, P.J. 1989. Remote sensing of foliar chemistry. Remote Sensing of Environment 30:271-278. 
de Beurs, K.M. and P.A. Townsend. 2008. Estimating the effect of gypsy moth defoliation using MODIS. Remote Sensing of Environment 112:3983-3990.

Driscoll, C.T., D. Whitall, J. Aber, E. Boyer, M. Castro, C. Cronan, C.L. Goodale, P. Groffman, C. Hopkinson, K. Lambert, G. Lawrence, and S. Ollinger. 2003. Nitrogen pollution in the northeastern United States: sources, effects, and management options. BioScience 53:357-374.

Eshleman, K.N., R.P. Morgan II, J.R. Webb, F.A. Deviney, and J.N. Galloway. 1998. Temporal patterns of nitrogen leakage from mid-Appalachian forested watersheds: role of insect defoliation. Water Resources Research 34:2005-2016.

Eshleman, K.N. 2000. A linear model of the effects of disturbance on dissolved nitrogen leakage from forested watersheds. Water Resources Research 36:3325-3335.

Eshleman, K.N., B.E. McNeil, and P.A. Townsend. 2009. Validation of a remote sensing based index of forest disturbance using streamwater nitrogen data. Ecological Indicators 9:476484.

Evans, J.R. 1989. Photosynthesis and nitrogen relationships in leaves of $\mathrm{C}_{3}$ plants. Oecologia 78:9-19.

Foster, D.R., F. Swanson, J.D. Aber, I. Burke, N. Brokaw, D. Tilman, and A. Knapp. 2003. The importance of land-use legacies to ecology and conservation. BioScience 53:77-88.

Foster, D.R. and J.D. Aber. 2004. Forests in Time. Yale University Press, New Haven.

Foster, J.R. and P.A. Townsend. 2004. Linking hyperspectral imagery and forest inventories for forest assessment in the Central Appalachians. Proceedings of the $14^{\text {th }}$ Central Hardwood Conference, March 17-19, 2004, USDA Forest Service General Technical Report.

Garnier, E., B. Shipley, C. Roumet, and G. Laurent. 2001. A standardized protocol for the determination of specific leaf area and leaf dry matter content. Functional Ecology 15:688-695.

Goodale, C.L. and J.D. Aber. 2001. The long-term effects of land-use history on nitrogen cycling in northern hardwood forests. Ecological Applications 11:253-267.

Hais, M., M. Jonasova, J. Langhammer, and T. Kucera. 2009. Comparison of two types of forest disturbance using multitemporal Landsat TM/ETM+ imagery and field vegetation data. Remote Sensing of Environment 113:835-845.

Haynes, K.J., A.M. Liebhold, and D.M. Johnson. 2009. Spatial analysis of harmonic oscillation of gypsy moth outbreak intensity. Oecologia 159:249-256.

Healey, S.P., W.B. Cohen, Y. Zhiqiang, and O.N. Krankina. 2005. Comparison of TasseledCap Landsat data structures for use in forest disturbance detection. Remote Sensing of Environment 97:301-310.

Healey, S.P., Z. Yang, W.B. Cohen, and D.J. Pierce. 2006. Application of two regression-based methods to estimate the effects of partial harvest on forest structure using Landsat data. Remote Sensing of Environment 101:115-126. 
Huang, C., S.N. Goward, K. Schleeweis, N. Thomas, J.G. Masek, and Z. Zhu. 2009. Dynamics of national forests assessed using the Landsat record: Case studies in eastern United States. Remote Sensing of Environment 113:1430-1442.

Huang, C., B. Wylie, L. Yang, C. Homer, and G. Zylstra. 2002. Derivation of a tasseled cap transformation based on Landsat 7 at-satellite reflectance. International Journal of Remote Sensing 23:1741-1748.

Jensen, J.R. 2007. Remote Sensing of the Environment: an Earth Resource Perspective. Prentice Hall series in geographic information science. Pearson Prentice Hall, Upper Saddle River.

Jin, S. and S.A. Sader. 2005. Comparison of time series tasseled cap wetness and the normalized different moisture index in detecting forest disturbance. Remote Sensing of Environment 94:364-372.

Johnson, D.M., A.M. Liebhold, and O.N. Bjørnstad. 2006. Geographical variation in the periodicity of gypsy moth outbreaks. Ecography 29:367-374

Kauth, R.J. and G.S. Thomas. 1976. The Tasseled Cap-a graphic description of the spectraltemporal development of agricultural crops as seen by Landsat. Proceedings of the Symposium on Machine Processing of Remotely Sensed Data, Purdue University, West Lafayette, Indiana. 4B41-4B51.

Kennedy, R.E., W.B. Cohen, and T.A. Schroeder. 2007. Trajectory-based change detection for automated characterization of forest disturbance dynamics. Remote Sensing of Environment 110:370-386.

Kokaly, R.F. 2001. Investigating a physical basis for spectroscopic estimates of leaf nitrogen concentration. Remote Sensing of Environment 75:153-161.

Latty, E.F., C.D. Canham, and P.L. Marks. 2004. The effects of land-use history on soil properties and nutrient dynamics in northern hardwood forests of the Adirondack Mountains. Ecosystems 7:193-207.

Likens, G.E., F.H.Bormann, N.M. Johnson, D.W. Fisher, and R.S. Pierce. 1970. Effects of forest cutting and herbicide treatment on nutrient budgets in the Hubbard Brook Watershed-Ecosystem. Ecological Monographs 40:23-47.

Likens, G.E., F.H. Bormann, R.S. Pierce, and W.A. Reiners. 1978. Recovery of a deforested ecosystem. Science 199:492-496.

Lovett, G.M. and P. Tobiessen. 1993. Carbon and nitrogen assimilation in red oaks (Quercus rubra L.) subject to defoliation and nitrogen stress. Tree Physiology 12:259-269.

Lovett, G.M., C.D. Canham, M.A. Arthur, K.C. Weathers, and R.D. Fitzhugh. 2006. Forest ecosystem responses to exotic pests and pathogens in eastern North America. BioScience 56:395-405.

Lovett, G.M., K.C. Weathers, M.A. Arthur, and J.C. Shultz. 2004. Nitrogen cycling in a northern hardwood forest: do species matter? Biogeochemistry 67:289-308. 
Luzadis, V.A. and E.R. Gossett. 1996. Sugar Maple. Pages 157-166 in: Lassoie, J.P., V.A. Luzadis, and D.W. Grover (editors). Forest Trees of the Northeast. Cooperative Extension Bulletin 235. Cornell Media Services.

MacArthur, R.H. and H.S. Horn. 1969. Foliage profile by vertical measurements. Ecology 50:802-804.

Martin, M.E., L.C. Plourde, S.V. Ollinger, M.-L. Smith, and B.E. McNeil. 2008. A generalizable method for remote sensing of canopy nitrogen across a wide range of forest ecosystems. Remote Sensing of Environment 112:3511-3519.

Martin, M.E. and J.D. Aber. 1997. High spectral resolution remote sensing of forest canopy lignin, nitrogen, and ecosystem processes. Ecological Applications 7:431-443.

Mash, J. 1996. The Land of the Living. Commercial Press, Cumberland.

McNeil, B.E. 2006. Spatial variability of foliar nitrogen in the Adirondack Park, New York. Doctoral Dissertation, Syracuse University.

McNeil, B.E., K.M. de Beurs, K.N. Eshleman, J.R. Foster, and P.A. Townsend. 2007. Maintenance of ecosystem nitrogen limitation by ephemeral forest disturbance: An assessment using MODIS, Hyperion, and Landsat ETM+. Geophysical Research Letters 34:L19406, doi:10.1029/2007GL031387.

McNeil, B.E., J.M. Read, T.J. Sullivan, T.C. McDonnell, I.J. Fernandez, and C.T. Driscoll. 2008. The spatial pattern of nitrogen cycling in the Adirondack Park, New York. Ecological Applications 18:438-452.

Ollinger, S.V., A.D. Richardson, M.E. Martin, D.Y. Hollinger, S.E. Frolking, P.B. Reich, L.C. Plourde, G.G. Katul, J.W. Munger, R. Oren, M.-L. Smith, K.T. Paw U, P.V. Bolstad, B.D. Cook, M.C. Day, T.A. Martin, R.K. Monson, and H.P. Schmid. 2009. Canopy nitrogen, carbon assimilation, and albedo in temperate and boreal forests: functional relations and potential climate feedbacks. Proceedings of the National Academy of Sciences 105:19335-19340.

Ollinger, S.V. and M.L. Smith. 2005. Net primary production and canopy nitrogen in a temperate forest landscape: An analysis using imaging spectroscopy, modeling, and field data. Ecosystems 8:760-778.

Pan, Y., J. Hom, J. Jenkins, and R. Birdsey. 2004. Importance of foliar nitrogen concentration to predict forest productivity in the Mid-Atlantic region. Forest Science 50:279-289.

Peterson, D.L. and G.S. Hubbard. 1992. Scientific issues and potential remote-sensing requirements for plant biochemical content. Journal of Imaging Science and Technology 36:446-456.

Rogan, J., J. Franklin, and D.A. Roberts. 2002. A comparison of methods for monitoring multitemporal vegetation change using Thematic Mapper imagery. Remote Sensing of Environment 80:143-156. 
Schaefer, W.D. and T.C. Brown. 1991. Ten Year Resource Management Plan: Savage River State Forest: Draft Document. State of Maryland, Department of Natural Resources, Public Lands Administration, State Forest \& Park Service.

Smith, M.-L. and M.E. Martin. 2001. A plot-based method for rapid estimation of forest canopy chemistry. Canadian Journal of Forest Research 31:549-555.

Smith, M.-L., S.V. Ollinger, M.E. Martin, J.D. Aber, R.A. Hallett, and C.L. Goodale. 2002. Direct estimation of aboveground forest productivity through hyperspectral remote sensing of canopy nitrogen. Ecological Applications 12:1286-1302.

Smith, M.-L., M.E. Martin, S.V. Ollinger, and L. Plourde. 2003. Analysis of hyperspectral data for estimation of temperate forest canopy nitrogen concentration: Comparison between an airborne (AVIRIS) and a spaceborne (Hyperion) sensor. EEE Transactions on Geosciences and Remote Sensing 41:1332-1337.

Teillet, P.M., B. Guindon, and D.G. Goodeonugh. 1982. On the slope-aspect correction of multispectral scanner data. Canadian Journal of Remote Sensing 8:84-106.

Townsend, P.A., J.R. Foster, R.A. Chastain, W.S.Currie. 2003. Application of imaging spectroscopy to mapping canopy nitrogen in the forests of the central Appalachian Mountains using Hyperion and AVIRIS. IEEE Transactions on Geoscience and Remote Sensing 41:1347-1354.

Townsend, P.A., K.N. Eshleman, and C. Welcker. 2004. Remote sensing of Gypsy moth defoliation to assess variations in stream nitrogen concentration. Ecological Applications 14:504-516.

Ustin, S.L., D.A. Roberts, J.A. Gamon, G.P. Asner, and R.O. Green. 2004. Using imaging spectroscopy to study ecosystem processes and properties. BioScience 54:523-534.

Vaieretti, M.V., S. Diaz, D. Vile, and E. Garnier. 2007. Two measurement methods of leaf dry matter content produce similar results in a broad range of species. Annals of Botany 99:955-958.

Vitousek, P.M. and W.A. Reiners. 1975. Ecosystem succession and nutrient retention: a hypothesis. BioScience 25:376-381.

Vitousek, P.M., J.R. Gosz, C.C. Grier, J.M. Melillo, W.A. Reiners, and R.L. Todd. 1979. Nitrate losses from disturbed ecosystems. Science 204:469-474.

Wessman, C.A., J.D. Aber, D.L. Peterson, and J.M. Mellilo. 1988. Remote sensing of canopy chemistry and nitrogen cycling in temperate forest ecosystems. Nature 335:154-156.

Wessman, C.A. 1992. Spatial scales and global change: bridging the gap from plots to GCM grid cells. Annual Review of Ecology and Systematics 23:175-200.

White, P.S. and S.T.A. Pickett. 1985. Natural disturbance and patch dynamics: an introduction. Pages 3-13 in: Pickett, S.T.A. and P.S. White (editors). The Ecology of Natural Disturbance and Patch Dynamics. Academic Press, Inc., Orlando. 
Wilson, E.H. and S.A. Sadar. 2002. Detection of forest harvest type using multiple dates of Landsat TM imagery. Remote Sensing of Environment 80:385-396.

Wright, I.J., P.B. Reich, M. Westoby, D.D. Ackerly, Z. Baruch, F. Bongers, J. Cavender-Bares, T. Chapin, J.H.C. Cornelissen, M. Diemer, J. Flexas, E. Garnier, P.K. Groom, J. Gulias, K. Hikosaka, B.B. Lamont, T. Lee, W. Lee, C. Lusk, J.J. Midgley, M.-L. Navas, U. Niinemets, J. Oleksyn, N. Osada, H. Poorter, P. Poot, L. Prior, V.I. Pyankov, C. Roumet, S.C. Thomas, M. Tjoelker, E.J. Veneklaas, and R. Villar. 2004. The worldwide leaf economics spectrum. Nature 428:821-827. 


\section{Lindsay N. Deel}

Graduate Research Assistant

Department of Geology and Geography

West Virginia University

161 Brooks Hall

P.O. Box 6300

Morgantown, WV 26505

Email: Ideel@mix.wvu.edu

\section{Education}

Ph.D. Geography

West Virginia University, Morgantown, WV

in progress

Advisor: Dr. Brenden McNeil

\section{M.A. Geography}

West Virginia University, Morgantown, WV

Advisor: Dr. Brenden McNeil

2010

GPA: 4.0

\section{B.A. Geographic Science}

James Madison University, Harrisonburg, VA

GPA: 3.9 - President's List 2008, Dean's List 2007

B.A. Camping, Recreation, and Outdoor Leadership

Eastern Mennonite University, Harrisonburg, VA

\section{Employment}

Graduate Teaching Assistant, Department of Geology and Geography, West 2010 -

Virginia University

Graduate Student Mentor, Research Experience for Undergraduates

(REU),West Virginia University

Graduate Research Assistant, Department of Geology and Geography, West Virginia University

GIS Technician, County of Page, VA

Undergraduate Teaching Assistant, Geography Department, James Madison University

\section{Professional Presentations}

Deel, L.N., P.A. Townsend, and B.E. McNeil. Assessing the cumulative impact of disturbance on canopy structure and chemistry in Appalachian forests. 95th Ecological Society of America Annual Meeting, Pittsburgh, PA. 1-6 August 2010. (poster) 
Deel, L.N., P.A. Townsend, and B.E. McNeil. Assessing the cumulative impact of disturbance on canopy nitrogen in Appalachian forests. Association of American Geographers Annual Meeting, Washington D.C. 14-18 April 2010. (paper session)

Deel, L.N., P.A. Townsend, and B.E. McNeil. Assessing the cumulative impact of disturbance on canopy structure and chemistry in Appalachian forests. Eberly College of Arts \& Sciences' Research Horizons Poster Day, Morgantown, WV. 6 April 2010. (poster)

Deel, L.N., P.A. Townsend, and B.E. McNeil. Assessing the cumulative impact of disturbance on canopy structure and chemistry in Appalachian forests. 2010 NASA Terrestrial Ecology Science Team Meeting, La Jolla, CA. 15-17 March 2010. (poster)

Curtis, P.G., L.N. Deel, and B.E. McNeil. Detecting the Impact of Disturbance on Forest Canopy Structure. Summer Undergraduate Research Symposium, Morgantown, WV. 30 July 2009. (poster)

McNeil, B.E. and L.N. Deel. Spectroscopic characterization of forest functional types: a leaf trait approach. Northeastern Ecosystems Research Cooperative, Durham, NH. 12-13 November 2008. (poster)

\section{Scholarships and Awards}

Graduate Teaching Assistantship (\$18,000), West Virginia University 2010 -

NASA WVSGC Graduate Research Fellowship (\$24,000), West Virginia University

Graduate Research Assistantship (\$18,000), West Virginia University 2008 - 2010

Outstanding Student, James Madison University 2008

Research Experience

Ph.D. Candidate, West Virginia University

Project: "Improving BASINS/HSPF predictions of nitrogen export to improve 2010 -

TMDL accuracy using NASA imagery"

Graduate Research Assistant, West Virginia University

Project: "Assessing the cumulative impact of disturbance on canopy nitrogen 2009 - 2010 in Appalachian forests"

Graduate Research Assistant, West Virginia University

Project: "Characterization of forest functional types and their role in

$2008-2009$

mediating ecosystem response to environmental change"

Undergraduate Research Assistant, James Madison University

Project: "Use of air photos, topographic maps and satellite imagery to improve the accuracy and add information to the Geographic Information System of the island of LaGonave, Haiti"

\section{Teaching Experience}

Graduate Student Mentor, Research Experience for Undergraduates 
(REU),West Virginia University (Grad 593a - Entering Mentoring)

Graduate Teaching Assistant, West Virginia University

Geog 452 - GIS Applications

Geog 494m - Geodemographics

Guest Lectures:

Geog 107 - Introduction to Physical Geography (2 lectures)

Geog 307 - Biogeography (2 lectures)

Undergraduate Teaching Assistant, James Madison University

Geog 265 - Thematic Cartography

Geog 366 - Geographic Information Science

Geog 468 - Internet GIS

$2007-2008$

Guest Lectures:

Geog 366 - Geographic Information Science (2 lectures, 1 lab)

GIS Tutor, James Madison University 2008

Outdoor Education Instructor, YMCA of the Rockies 2004

Memberships and Affiliations

Student Co-Director, Remote Sensing Specialty Group, Association of American Geographers

President, American Society for Photogrammetry and Remote Sensing (ASPRS) Student Forum, WVU

Vice-President, Gamma Theta Upsilon (GTU), WVU

$2010-$

Co-chair, Colloquium Planning Committee, WVU

2009

Graduate Representative, Geography Program, WVU

2009

Member, American Geophysical Union (AGU)

2009

2009

Member, Biogeochemistry/Ecosystems Journal Club, WVU

2009 -

Member, Ecological Society of America (ESA)

2009

Secretary, Geography Graduate Group, WVU

2009 -

Northeastern Ecosystems Research Cooperative (NERC)

$2008-2009$

Graduate Representative, Department of Geology and Geography, WVU

2008

Member, Association of American Geographers (AAG)

$2008-2009$

$2006-$

Member, American Society for Photogrammetry and Remote Sensing (ASPRS) 2006 -

Member, Geography Club, JMU

$2006-2008$

Copy Editor, The Weather Vane newspaper, EMU

$2003-2004$

Software Proficiencies

GIS: ESRI ArcGIS, GeoDa 
Remote Sensing: ERDAS Imagine, ENVI, ESRI ArcGIS

GPS: Trimble Geo-XT and Geo-XH, Pathfinder Office, Terrasync, Garmin eTrex series Statistics: JMP, Microsoft Excel, the Unscrambler

General: Microsoft Office Professional 2007

ESRI Certification Courses:

Learning ArcGIS Desktop (24 hours)

Basics of the Geodatabase Topology with ArcGIS Desktop (6 hours)

Creating and Editing Geodatabase Topology with ArcGIS Desktop (6 hours)

Creating and Editing Geodatabase Features with ArcGIS Desktop (6 hours)

Creating, Editing, and Managing Geodatabases for ArcGIS Desktop (12 hours)

Understanding GIS Queries (3 hours)

Working with Rasters in ArcGIS Desktop (9 hours) 